\title{
EL CONTROL DEL ESPACIO ARQUITECTÓNICO EN LAS RUINAS DE LA IGLESIA DE SANTA MARÍA DE CAZORLA.
}

\author{
JESÚS ESTEPA RUBIO \\ Universidad Politécnica de Cartagena \\ ANTONIO ESTEPA RUBIO \\ Universidad San Jorge
}

\begin{abstract}
Resumen
Para el diseño de los edificios, así como su posterior puesta en obra, los arquitectos del Renacimiento utilizaban procedimientos de trabajo y sistemas de control basados en el conocimiento de la geometría y de las matemáticas, cuyo objetivo se focalizaba en conseguir resultados técnicos y formales que acercan la arquitectura a proporciones y armonías que definen el sentir general del hombre de este nuevo tiempo.

La arquitectura no es fruto del azar ni de decisiones tomadas a la ligera, sino que muy al contrario cada parte de ella se relaciona con las demás y con la totalidad del conjunto, utilizando para ello criterios técnicos y sistemas métricos y de control formal y espacial que cifran y codifican los modos clásicos empleados en la creación arquitectónica. La revisión de los tratados arquitectónicos y de sus "instrucciones de montaje" hace posible extraer conclusiones que se pueden repetir sistemáticamente en edificaciones renacentistas de igual tipología constructiva. A la luz de ello podemos pues verificar ciertos aspectos que para el caso que nos ocupa en Cazorla, complete los datos inexistentes que culminarían por completar el espacio inconcluso de esta edificación.
\end{abstract}

\section{Palabras clave}

Vandelvira. Renacimiento Andaluz. Cantería. Geometría. Proporción. Modulación.

\section{CONTROL OF THE ARCHITECTURAL SPACE IN THE RUINS OF SAINT MARY OF CAZORLA CHURCH.}

\begin{abstract}
For the design of buildings, and also for build they later, the architects of the Renaissance used workflows and control systems based on the knowledge of geometry and mathematics. Their targets were focused on reach technical and formal outputs that joint the architecture to proportions and harmonies according with the general feeling of men in those new times.

Architecture is not the result of chance or decisions taken lightly, but rather on the contrary each part is related to the others and to the whole of the building, using for this technical concepts and, metrical systems and spatial and formal controls. All together encode the classical modes used in architectural creation.

The review of the architectural treaties and its "assembly instructions" make possible to obtain conclusions we can repeat systematically in several building of Renaissance with same typology. Looking at this we can therefore verify certain aspects that for our study case in Cazorla, complete the nonexistent data that would culminate in completing the unfinished space of this building.
\end{abstract}

Key words

Vandelvira. Andalusian Renaissance. Stonework. Geometry. Proportion. Modulation.

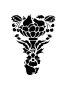




\section{Principios de partida. Aproximación conceptual.}

No puede pasar desapercibida la notable admiración que las obras arquitectónicas del Renacimiento andaluz nos producen al contemplarlas, y como consecuencia de ello, abundando en nuestra sorpresa y emoción, necesitemos aún hoy día encontrar respuestas concretas y precisas acerca de cómo éstos nuevos artistas operaban tanto para concebir el diseño arquitectónico del edificio como para después organizar todo un sistema constructivo que a priori podría parecernos extremadamente complejo.

Parece absolutamente necesario que, desde los comienzos iniciales de la obra, aún no más allá de la propia mente del arquitecto, todo siga un plan. Todo tiene que estar regido por parámetros y reglas que, dependiendo de las diferentes etapas por las que la obra vaya pasando, marquen las pautas y los modos de proceder conducentes no ya sólo a un diseño específico y concreto, sino además a un conjunto de ideas y de principios que son característicos y tremendamente definitorios del tiempo en que ahora se trabaja.

Una de las posibles claves de lectura está representada por la búsqueda de instrucciones geométricas y principios numéricos y teóricos compositivos que subyacen en la construcción, para que de este modo la arquitectura verifique una idea. La idea arquitectónica está inexorablemente ligada a todo edificio, y si ahora algo importa al nuevo arquitecto del Renacimiento es que ella sea el eje motriz del resultado finamente construido; una vez concluida, la obra no puede dejar de ser aquello que originalmente y de forma muy abstracta nació en la mente del arquitecto.

La arquitectura surge pues de algo sencillo, de una necesidad específica ligada al comportamiento y a las necesidades derivadas de los modos de vida y de la cultura de una civilización; pero en su solución física no basta ya sólo con dar cabida a respuestas materiales, sino que además todo tiene que formar parte de un modo de comprender al hombre y a su espíritu mucho más general y a la vez abstracto. Así pues, la idea del proyecto es la ligazón que justifica todas y cada una de las decisiones que el proyectista va tomando hasta concluir la obra. Es aquí donde la geometría y por ende el control de las organizaciones espaciales, funcionales, constructivas, incluso ornamentales, juegan un papel determinante.

El uso de la geometría parte de la incipiente necesidad de delimitar espacios y superficies para satisfacer necesidades de carácter práctico, ligadas a problemas métricos relativos a la agrimensura; aunque pronto se convirtió en un medio válido para la definición y el control formal, espacial e incluso constructivo de la puesta en obra del conjunto arquitectónico ideado con un fin particular e inherente al propio encargo del proyecto.

Los arquitectos del Renacimiento se reafirman pues en la importancia que tiene la geometría para el proyecto arquitectónico como instrumento de control, no ya sólo gráfico y formal, sino también espacial. Así pues la desmaterialización es el código de verificación de la corrección arquitectónica y su adecuado funcionamiento a propósito de los nuevos inputs introducidos con el emergente ideal del hombre ilustrado y culto de esta época, y sus aparentes necesidades de encontrar un equilibrio y una armonía consonante con la percepción que éste tiene del universo.

Llevado esto al caso particular de las ruinas de la Iglesia de Santa María de Cazorla podríamos tener un punto de partida que se configura en un nuevo escenario que nos ayuda, sin necesidad de ver más de lo que realmente existe, a completar los datos inexistentes que conectan el conjunto de informaciones geométricas y espaciales que podemos medir de forma empírica en sus restos arqueológicos. Es decir, podríamos generar un conjunto de plantillas y códigos de control que se pudieran superponer a los vestigios de aquella obra que nunca llegó a ser finalizada para que de este modo podamos abstraer la percepción espacial y el germen de proyecto que el autor de su traza, Andrés de Vandelvira ${ }^{1}$, hubo imaginado para el edificio.

${ }^{1}$ Es muy escasa la documentación existente relativa a la atribución de la autoría de la obra de Santa María de Cazorla, pero según Chueca Goitia, basándose en la existencia de muchos elementos comunes con otras obras existentes y de autoría atribuida al arquitecto Andrés de Vandelvira, ésta es de la firma del mismo autor. Chueca Goitia hace hincapié en que la obra fue gestada por Vandelvira, y para ello se apoya en los códigos de control de la forma y dimensiones de su espacio que el investigador reconoce a través de su geometría. No en 
Para el conocimiento de los componentes arquitectónicos de la Iglesia de Santa María de Cazorla es indispensable determinar un procedimiento basado en el análisis de sus ruinas que permita establecer un acercamiento que dépor fruto el conocimiento integral de la obra ${ }^{2}$.

El método de análisis se basa en el estudio de dos cualidades: por un lado la geometría y por otro lado el espacio. Esto da lugar a un análisis geométrico y espacial que sistematiza el estudio de las ruinas.

Atenderemos a conceptos geométricos y al tratado arquitectónico como herramientas básicas que nos permiten iniciar un análisis que desemboque en el establecimiento de conclusiones que muestren como resultado los modelos germinales de la traza.

Una vez despiezados los diferentes elementos arquitectónicos que constituyen el edificio, éstos se estudian independientemente según un análisis comparativo basados en criterios de continuidad morfológica y cronológica dentro de un repertorio de obras de similares características; así pues se determinan las cualidades de cada fuste, cornisa, entablamento, pedestal, ventana, arco, bóveda y capitel, siguiendo siempre como patrón las medidas y proporciones que indican los órdenes clásicos.

A pesar de que esta tarea pudiera parecer, quizá por extensa, demasiado compleja, en realidad no lo es tanto, pues existen determinados elementos que cualifican a la totalidad de relaciones métricas y dimensionales del edificio, tal y como sucede por ejemplo con los soportes, esto es, los pilares, las columnas y las pilastras, que marcan los ritmos compositivos y la lógica numérica y dimensional de la totalidad de la obra. Los soportes son las piezas del edificio donde podemos reconocer claramente los miembros arquitectónicos presentes en la arquitectura clásica romana. Es por ello, que para el estudio de estos elementos podremos apoyarnos, en parte, en la tratadística que durante los siglos XV y XVI fue apareciendo en Italia para, posteriormente, llegar a España.

En 1562 Vignola publica su tratado Regoledelli cinque ordine d'architettura, editada por primera vez en castellano en 1593. Éste fue el tratado sobre arquitectura clásica, basado en el original de Vitruvio ${ }^{3}$, más extendido no sólo en el Renacimiento, sino que fue utilizado

balde presenta un primer dibujo en sección donde por necesidad formal y coherencia espacial y geométrica, se atisba la totalidad del espacio arquitectónico hoy inexistente, pero que nunca llegó a materializarse. También Molina Reyes, a la vista de posteriores revisiones más detalladas y pormenorizadas sobre la producción del maestro alcaraceño, refuerza la hipótesis sobre la autoría de Andrés de Vandelvira, si bien añadiendo algunas matizaciones. Molina Reyes dice que la portada lateral y los piesno se insertan exactamente dentro del lenguajevandelviriano, alineándose con las formas tardíasdel Quinientos. Por el contrario, los restos delPresbiterio sí son más propios de Vandelvira (así lomuestran los machones con semicolumnas corintiasy fuste acanalado con baquetones alternantes), laestructura de la bóveda de cañón acasetonada, laventana serliana del tímpano del presbiterio y, porsupuesto, la escalera de caracol rematada en lapequeña linterna cilíndrica.Parece clara, por tanto, que la cabecera si se insertadentro de la maestría de Vandelvira, sin embargolos pies se alejan un tanto de su estilo, e inclusocronología. En este caso se ha señalado el nombrede quien grabó su acróstico en la fachada de latorre, Alonso Barba.

2 Ricardo Sierra Delgado propone una forma de trabajo conducente al entendimiento del espacio arquitectónico de la capilla rotonda siloesca basado en una reconstrucción virtual del proyecto de la Sacra Capilla del Salvador de Úbeda a partir del análisis del documento escrito dejado por Diego de Siloé. En este estudio se establece un cotejo dimensional comparado de los elementos arquitectónicos de la capilla ubetense frente a la Capella Pellegrini de San Bernardino de Verona, obra de Michele Sanmicheli.

3 Según Juan Francisco Esteban Lorente, Vitruvio considera el cosmos, el hombre y la arquitectura sometidos a las armonías musicales y geométricas, y explica en su texto la necesidad de someterse a ellas para que la percepción que el hombre tiene de la arquitectura sea la adecuada. Si bien conocemos a Vitruvio por su tratado de arquitectura, escrito y dedicado al emperador Augusto hacia el año 15 a.C. en realidad tenemos una idea real de su contenido gracias a las interpretaciones que los maestros renacentistas hacen de él y que condicionan muchas de las decisiones de proyecto generadas a la luz de las directrices del texto. Esteban Lorente se detiene en destacar la oscuridad del pensamiento vitruviano, de lo que el propio Vitruvio avisa y alerta en la introducción de su Libro V, cuando en el capítulo 4 aborda el tema de la definición de la armonía. Por otra parte hemos de considerar que Vitruvio no se propone dar explicaciones de matemáticas u otra ciencia, sino crear una compilación ordenada y sistemática de los diversos conocimientos sobre la construcción; en resumen una compilación divulgadora para lectores interesados y formados al respecto. 
como catálogo para la composición hasta pasada la primera mitad del siglo $\mathrm{XX}^{4}$ (Jiménez Martín, 1975), con ediciones como la de Carreras Soto (Carreras Soto, 1952).

\section{Teoría de la proporción arquitectónica. Mecanismos de control formal y espacial.}

Proporciones y control formal y espacial de la arquitectura.

El concepto de proporción aplicado a la creación arquitectónica está presente en todas las épocas con relaciones distintas, con mayor o menor importancia, pero presente de todos modos. Son casi innumerables los autores que han dedicado su atención a intentar definir su significado y por lo tanto a intentar atribuir valores concretos y relaciones métricas que vaticinen sus hipótesis al respecto. Viollet le Duc dedica a ello un notable espacio en su diccionario de arquitectura, donde además compara este concepto con otros tales como el de simetría y el de dimensión ${ }^{5}$

El concepto matemático de proporción ha influido notablemente en el trabajo de los arquitectos del Renacimiento, de modo que en la búsqueda de relaciones geométricas muchos de ellos han asignado un papel fundamental a significados místicos o filosóficos, hasta el punto que determinados valores, como por ejemplo la sección áurea podrían ser a la vez regla de medida y también religión.

En la creación arquitectónica, normalmente las cosas no surgen de caprichos ni de situaciones surgidas al azar, sino que más bien sucede lo contrario, y prueba de ello es la extraordinaria complejidad de procesos mentales concatenados que se reconocen en toda obra de arquitectura. Está claro, que es amplísima la variedad y la gama de decisiones que tiene que tomar un arquitecto durante el proceso de ideación de un proyecto, pues a la base primaria del plano funcional que debe regir toda obra arquitectónica constantemente se adhieren necesidades fluctuantes que bien nacidas del promotor de la obra, de las condiciones históricas, económicas o sociales del momento, o bien nacidas del propio arquitecto, condicionan la personalidad intrínseca del resultado de dicho trabajo.

La arquitectura siempre ha tenido un papel determinante en la historia de la humanidad, que deriva sin duda del hecho de que el hombre no puede vivir sin la adaptación del medio físico concretada a través de esta disciplina, y es notorio que los puntos de énfasis que modifican las condiciones del proyecto han sido variables para cada época. Sin embrago es probable que en todo el proceso evolutivo que ha vivido la arquitectura desde el origen del hombre, cada uno de aquellos aspectos que en cada época fue enfatizado, haya dejado una huella imborrable que nos conduce a que sin tener consciencia de ello y sin buscarlo tengamos en cuenta sus consecuencias a la vez que sus logros y sus condiciones para los sucesivos. Es decir, la arquitectura tiene una inexpugnable condición de supervivencia por decantación, que permite la posibilidad de que cada época cuente con todo el bagaje de épocas anteriores para poder mejorar y maximizar la calidad del producto arquitectónico, independientemente de que tal situación finalmente se produzca o no, pues en demasiadas ocasiones podemos observar cómo se construyen edificios que parecieran haber olvidado todo lo aprendido o que hicieran caso omiso de aquello, aunque claro está quizás sea este aspecto fundamental el que sirva para marcar la linde entre aquello que puede englobarse dentro de la producción realmente arquitectónica y lo que simplemente es construcción.

\footnotetext{
${ }^{4}$ Sobre este aspecto podemos encontrar una referencia de Alfonso Jiménez, donde se hace mención del uso del tratado de Vignola en las escuelas de arquitectura durante el siglo XX, como única referencia para el conocimiento de la arquitectura clásica.

${ }^{5}$ Según Caterina Pallestini el texto de Viollet le Duc alude al término proporción con el concepto que tenían los griegos para designar aquello que nosotros entendemos como simetría, y que nada tiene que ver con el término real de proporción. De hecho un edificio puede ser simétrico y no haber sido construido según las proporciones convenientes o adecuadas; de modo tal que se deben entender las proporciones como las relaciones entre las partes y el todo, las relaciones lógicas, necesarias y capaces de satisfacer al mismo tiempo a la razón y a los ojos. Pallestini hace también necesario establecer una distinción entre las proporciones y las dimensiones, pues las dimensiones indican simplemente altura, longitud y superficie, mientras que las proporciones son relaciones relativas entre las partes de un todo, atendiendo a una determinada ley.
} 
Originalmente la arquitectura busca la creación de sistemas que modifiquen las cualidades del espacio para dotarlo de una funcionalidad que solucione una necesidad humana para la cual el medio físico en estado natural no está suficientemente preparado ${ }^{6}$; es decir, la arquitectura modifica lo natural para satisfacer unas necesidades funcionales derivadas de la actividad humana. Ahora bien, por ser la arquitectura una producción humana derivada de su intelecto, las formas de adaptar lo natural a la necesidad del hombre se ven modificadas por cuestiones anejas que imprimen características inherentes del propio individuo que ejecuta tal acción; ejemplo notorio de ello y que se manifiesta muy claramente es el tema de la decoración, el ornato que cualifica lo pragmático para converger con el interior del usuario.

Entre las definiciones de arquitectura existe una controversia entre la propuesta de William Morris y la de Adolf Loos, ya que Morris expresa que las personas no podemos ser indiferentes ante la presencia de arquitectura, ya que formamos parte de una civilización, y por ende debemos de estar atentos al conjunto de modificaciones que se realicen en el ambiente físico en el cual nos desarrollamos, de tal forma que la arquitectura es el variado mundo de las formas que determinan los espacios en los que nos desenvolvemos; además Morris presenta una propuesta de diseño la cual define como una actitud de crear, la misma que está presente en las casas, edificios, portadas de libros, etc., y diseñar que es la actividad de creación la cual es útil para el desarrollo de la vida humanan.

Adolf Loos alega que la arquitectura es un peligro para la civilización, que es el retroceso cultural, además que el arquitecto es un personaje agresivo que atenta ante la paz de un paisaje $^{7 .}$ Loos señala que las casas, edificaciones y objetos en general no requieren de arquitectura, sino más bien las construcciones deben ser sencillas para usos simples y certeros. Para Loos la arquitectura es capaz de incitar estados de ánimo y sentimientos y por ello afirma que no debería tomársela como un arte ya que sólo una parte, muy pequeña, de la arquitectura corresponde al dominio del arte: el monumento funerario y conmemorativo.

Las formas de enfocar una misma casuística para resolver un problema funcional son infinitas, tal y como la historia de la arquitectura se ha encargado de demostrar, pero en todas y cada una de ellas aparecen singularidades, que sin olvidar el punto de convergencia común, tratan de evocar principios que responden a planteamientos sociales, políticos, técnicos o cualquier otro definitorio de una época.

En el Renacimiento, el hombre recupera principios de la época clásica para generar soluciones que den respuesta a los planteamientos de un momento de la historia que lucha por romper con la mirada medieval, y para ello su mirada enfoca en ellos mismos, haciendo al hombre el centro de atención y el protagonista de este nuevo planteamiento. Las condiciones anejas a las soluciones arquitectónicas que modifican el medio físico, tratarán de conseguir captar la atención sobre todo lo demás, incluso sobre Dios, para centrarla en el ser humano.

Tal y como ya se ha comentado la arquitectura también es tratada para ser adaptada a estas nuevas condiciones en las que el hombre se erige en perfecto protagonista, y es por ello por lo que se tienen que idear procedimientos que partiendo del análisis geométrico busquen tal adecuación. La geometría y el estudio de las proporciones y las relaciones métricas entre las cosas serán herramientas básicas para poner en juego tales ideales humanistas; será entonces a partir de tales estudios cuando nazca la perspectiva, que se convertirá en un esquema regulador para adaptar la producción arquitectónica a la percepción del ser humano.

La perspectiva ${ }^{8}$ es el sistema gráfico de representación que permite comprobar la percepción que tiene el ser humano sobre el espacio, y de aquí el hecho de que la

arquitectura la utilice para garantizar que lo que se construye es percibido por el hombre consiguiendo los postulados del ideal humanista. La arquitectura y el urbanismo se trazan a

\footnotetext{
${ }^{6}$ Morris, W.; 1881. Prospects of Architecture in Civilization

${ }^{7}$ Loss, A., 1910. Arquitectura

${ }^{8}$ Gentil Baldrich, J.M., 2014. Perspectiva cónica e ideología en el Arte. A través de la mirada: anatomía, arquitectura y perspectiva en la tradición artística occidental.ISBN: 978-84-15289-89-0, págs. 145-186. Madrid: Ed. Abada.
} 
partir de este momento siguiendo los postulados perspectivos que comienzan a consensuarse guiados por los análisis de estudios tales como los de Piero de la Francesca, Leon Battista Alberti o Filippo Brunelleschi, en los que por fin se descodifican los mecanismos geométricos que basándose de un modo aún somero en la geometría proyectiva permiten conocer de antemano cómo el hombre percibirá aquello que se pretende construir.

La definición de espacialidad del Renacimiento es la incorporación de la perspectiva como instrumento del proyecto arquitectónico y la noción de diseño como forma de conocimiento.

La principal ruptura con el espacio medieval se produce en el momento en que los arquitectos del Renacimiento pasan a diseñar en sus edificios un desarrollo en el que las reglas del diseño son fácilmente asimilables por los usuarios del mismo. A partir de un análisis objetivo del espacio, presidido por un cierto sentido empírico, llegan a conclusiones que impondrán el propio ritmo del edificio y su entorno.

El dominio del lenguaje clásico, para hacer llegar estos efectos útiles en los edificios, hace posible el estudio de la perspectiva. Como resultado, surge una arquitectura insertada en un espacio perspectivo, integralmente aprehendido por el observador y cuyas relaciones proporcionales se muestran de forma analítica y objetiva.

Estas nuevas relaciones espaciales son especialmente evidentes comparadas con el espacio presente en las catedrales góticas. En ellas, la intención arquitectónica es que el observador, desde el momento en que entra en el edificio, sea dominado por el espacio e instintivamente alce su mirada hacia la cima, procurando así un movimiento ascendente en busca de la figura de Dios. En otras palabras, toda monumentalidad de este espacio gótico tiene una función, entre otras, que es poseer la voluntad del individuo y determinar sus deseos, la función de su estancia y el uso del edificio. En el espacio renacentista, la intención es justamente la contraria: el edificio no domina al individuo, sino que éste reflexiona sobre su espacialidad y la maneja. Se traslada el concepto de una arquitectura a la medida de Dios a la de una a la medida del hombre.

Con ello inmediatamente surgen necesidades arquitectónicas venidas a posteriori, tales como son aquellas que normalmente derivan de las condiciones de ornato. El conocer lo que el hombre percibe redundará en la necesidad de que tal percepción sea agradable para él, y por lo tanto aparecen convencionalismos que utilizan la geometría y sus relaciones matemáticas y métricas, para establecer proporciones que garanticen armonía, serenidad y equilibrio en la percepción del espacio arquitectónico que había nacido de la necesidad funcional que brota de la actividad humana.

Por primera vez se atiende a la actividad arquitectónica como una composición' ${ }^{9}$; es decir, al igual que en la pintura cada elemento tiene que encajar en su sitio para que la percepción del mismo agrade al intelecto perceptivo, la arquitectura ahora también tiene la obligación de que cada una de sus partes encaje con las demás de acuerdo con unos criterios, que derivados del análisis perceptivo y visual, complazcan no ya sólo la necesidad utilitaria de ser humano, sino también sus gustos y sus deseos. La arquitectura, ahora también tiene una labor expresiva, es un medio de comunicación en el que el lenguaje se compone a través de la geometría.

Las proporciones buscan el equilibrio compositivo y justifican la manera con la que se organizan los elementos que intervienen en la obra arquitectónica. Las columnas, los frisos, los capiteles, las cubiertas, las ventanas, y en general todos los recursos arquitectónicos se tabulan en códigos de control que, basados en módulos escalables para cada edificio según las proporciones que se requieran por la cantidad de su uso programático, sistematizan la geometría para que los órdenes clásicos no se vean desvirtuados y que sus percepciones se encuadren dentro del ideal cognoscitivo del ser humano. El mejor ejemplo de ello es el tratado de Vignola ${ }^{10}$ en el que pormenoriza en detalles gráficos y métricos para el trazado de los cinco órdenes clásicos de la arquitectura.

\footnotetext{
${ }^{9}$ Hodgson Torres, M. L., 2004. Dibujo y conocimiento. La investigación a través de la forma. Revista ARSDIDAS, número 1, Tenerife. Depósito Legal TF2336/2004, ISSN: 1698-9074

${ }^{10}$ Carreras Soto, T., 1952. Trazado de los cinco órdenes de arquitectura. Sevilla: Ed. Casa Carreras.
} 
Resulta interesante analizar cómo la geometría de la traza de muchos edificios arranca de relaciones matemáticas diversas, entre las cuales la divina proporción ${ }^{11}$ tiene especial calado y aceptación. Tal proporción, por estar presente en los mecanismos compositivos de la generación formal de innumerables individuos de la naturaleza, presenta relaciones que producen percepciones armónicas y naturales de lo arquitectónico, entendiendo esto, tal y como ya se ha apuntado con anterioridad, como una modificación del medio físico natural para adaptarlo a unas necesidades funcionales impuestas por el ser humano. Es decir, si lo artificial se percibe desde un conocimiento sensorial similar al que produce lo natural, entonces aquello nos resultará más armónico y asimilable.

Sin embargo, estos planteamientos no permanecerán en la arquitectura de forma permanente e imperecedera y a partir del siglo XVIII se inicia un proceso de ruptura con la armonía de las proporciones geométricas para lo construido.

Quien mejor expresó estas críticas fue el filósofo inglés David Hume, para quien todo razonamiento no es más que una especie de sensación, cambiando así la dirección de la estética desde lo objetivo hacia lo subjetivo, de modo que la belleza no depende del objeto, siempre que dicho objeto concuerde con la armonía universal. Afirma que la reglas artísticas derivan de la experiencia y de los sentimientos comunes a toda la humanidad.

Burke en 1757 niega que la belleza tuviera algo que ver con el cálculo y la geometría. Desde este momento la proporción se convirtió en un asunto de sensibilidad individual, y el arquitecto se liberó por completo de la esclavitud de las proporciones matemáticas.

El teórico Ruskin declaró que había tantas proporciones posibles como melodías musicales y que debía dejarse en manos de la inspiración del artista la invención de proporciones bellas ${ }^{12}$.

La demolición del sistema clásico se concluye con ataques como "han recurrido a combinaciones cabalísticas, a no sé qué propiedades misteriosas de los números o, más aún, a analogías como las que encuentra la música entre las numerosas vibraciones que determinan los acordes. No son más que quimeras. Las proporciones son infinitas". Estas son algunas frases de un texto francés de 1915 usado en la Ecole de Beaux-Arts de París.

Sin embargo las proporciones volverán a la arquitectura con la llegada del arquitecto y pintor suizo-francés, Charles-Edouard Jeanneret (1887-1965), apodado Le Corbusier, que establecerá su uso como un referente ineludible desde sus primeros trabajos, llegando, después de una intensa tarea de investigación, a establecer un sistema de proporciones propio que denominó El Modulor ${ }^{13}$, y que se basaba en la altura del hombre con el brazo levantado.

11 Reyes Iglesias, M. E., 2010. Arte y Naturaleza en clave geométrica. Valladolid. Departamento de Matemática Aplicada. Universidad de Valladolid.

12 Ruskin, J. 1849. Las siete lámparas de la arquitectura.

13 Sistema de medidas detallado por Le Corbusier, quien publica en 1948 el libro llamado Le Modulor seguido por Le Modulor 2 en 1953 en los que da a conocer su trabajo, y de cierta manera, se une a una larga tradición vista en personajes como Vitruvio, Da Vinci y Leon Battista Alberti en la búsqueda de una relación matemática entre las medidas del hombre y la naturaleza. De cierta manera es una búsqueda antropométrica de un sistema de medidas del cuerpo humano en que cada magnitud se relaciona con la anterior por el número áureo, todo con la finalidad de que sirviese como medida base en las partes de la arquitectura.

Las medidas parten desde la medida del hombre con la mano levantada $(226 \mathrm{~cm})$ y de su mitad, la altura del ombligo $(113 \mathrm{~cm})$. Desde la primera medida multiplicando sucesivamente y dividiendo de igual manera por el número de oro se obtiene la llamada serie azul, y de la segunda del mismo modo la roja. Siendo cada cual una sucesión de Fibonacci y permitiendo miles de combinaciones armónicas. Le Corbusier elabora una parrilla de proporciones según los criterios siguientes:

La parrilla parte de tres medidas: 113, 70, 43 (en $\mathrm{cm}$ ), que están en relación $\varnothing$ (divina proporción) $43+70=113$, ó $113-70=43$.

Adicionadas dan: $113+70=183$ (la altura del hombre promedio según Le Corbusier); $113+70+43=226$ (hombre con el brazo arriba).

SERIE ROJA: toma la medida 113 proporciona la sección áurea 70; los números son: 4-6-10-16-27-43-70113-183-296, etc.

SERIE AZUL: toma la medida 226 (113×2) proporciona la sección áurea 140-86: los números son: 13-2033-53-86-140-226-366-592, etc. 
Procesos y contenidos. Del papel a la obra.

Tal y como ya hemos abordado, la organización de la labor del arquitecto fue por primera vez analizada por Vitruvio, cuyo libro primero comienza distinguiendo entre la parte teórica de la arquitectura, a la que él llama ratiocinatio y la parte práctica y constructiva a la que denomina fabrica; será mucho más adelante cuando enuncie su famoso postulado sobre las tres cualidades básicas de la arquitectura: firmitas, utilitas y venustas.

Dicho esto y una vez que Vitruvio profundiza en la parte teórica de la arquitectura, define para ella seis conceptos básicos que siempre han de ser tenidos en cuenta tanto para la génesis de la obra arquitectónica como para la formalización y materialización de la misma: ordinatio, dipositio, eurythmia, symmetria, decor y distributio14.

Ordinatio significa adecuado tamaño, modulación proporción y correcta distribución de las diversas partes de un edificio. Se trata de la ordenación y modulación de todas y cada una de las diferentes partes que componen la obra, utilizando para ello un módulo o unidad dimensional básica que depende de forma inmediata de la dimensión de la fachada principal del edificio.

Compositio significa para Vitruvio la aplicación del sistema de proporciones a las distintas piezas que constituyen individualmente la totalidad de la obra, tomando para ello como referencia el módulo que ya ha sido establecido al determinar la anchura del edificio. Así pues como el propio Vitruvio indica la compositio nace de la simetría y ésta de la proporción, que a su vez queda referida a una razón o cociente entre los valores numéricos de las distintas fracciones del módulo empleado.

Dispositio significa lo que hoy podríamos traducir por proyecto. Es el conjunto de ideas que incluyen en su interior la explicación y las justificaciones de forma y geometría que se han seleccionado y utilizado para configurar el objeto del encargo asignado al arquitecto. La dispositio tiene por tanto ya un eminente y relevante peso gráfico, para dar lugar con ello al conjunto de dibujos y de planos que, siendo fruto del estudio, del conocimiento y de la invención del arquitecto, sirven para llevar al terreno y a la construcción el diseño elaborado. Así, San Isidoro de Sevilla alude a este concepto explicando lo siguiente: cuando se ve una obra realizada con magnificencia se ensalza al dueño por el coste de la obra; si se ve que el trabajo está hecho con habilidad se elogia la destreza del albañil; pero si el edificio alcanza su mérito por elegancia, proporciones y simetría, la gloria será para el arquitecto.

Eurythmia significa el bello y grato aspecto que resulta de la disposición de todas las partes de la obra, como consecuencia de la correspondencia entre la altura y la anchura de éstas con la longitud, de modo que el conjunto tenga las proporciones debidas. Vemos como Vitruvio, al definir este concepto, expone cómo los espacios de cada habitación están sometidos a razones, pero a la vez se determinan en razón a la contigua y a la principal. Así pues la eurythmia podría traducirse literalmente como el control del espacio arquitectónico pues de forma tajante afirma que en nada debe poner el arquitecto mayor cuidado que en hacer que los edificios tengan las medidas justas y proporcionadas entre el conjunto y las partes que lo componen. Por lo tanto, cuando se haya determinado la regla de la simetría, y se hayan reducido mediante el cálculo las relaciones de esta medida moduladora, entonces es llegado el momento de atender con inteligencia a la naturaleza del lugar, al uso y al aspecto externo del edificio; y quitando o añadiendo algo a las proporciones ya establecidas, llegar al modo y tamaño que le corresponda. Es pues que ello hace patente que la diferencia entre el propietario y el arquitecto estribe en que el primero no puede saber lo que será una obra hasta que no la vea concluida; en cambio, el arquitecto una vez tenga formada en su mente la idea, ve, aún antes de emprender la obra, el efecto futuro de su belleza, de su utilidad y de su decoro. Con ello pues Vitruvio no da una lección magistral sobre cómo proceder para el caso que nos ocupa en la Iglesia de Santa María de Cazorla, cuya imagen e impronta hubo de tener Vandelvira presente.

${ }^{14}$ Esteban Lorente, J. F., 2001, La teoría de la proporción arquitectónica en Vitruvio, Revista Artigrama, núm. 16, p. 229-256, ISSN: 0213-1498. 
Symmetria significa simultáneamente proporción y razón. Este término es utilizado por Vitruvio no con el significado que hoy día tiene para nosotros, sino que muy distintamente alude al conveniente tamaño que ha de tener una parte y la totalidad del conjunto en función del patrón modulador que organiza toda la obra. Por symmetria podemos entender el conjunto de todas las posibles combinaciones de proporciones que pueden encontrarse en una obra. La symmetria, a la que alude constantemente como regla de simetría, nace de la proporción y ésta de la razón (cociente); todas ellas conforman la eurythmia.

Decor significa hermosura, ornamento, conveniencia o decoro. No es otra cosa que la correcta adecuación de la forma a la función y con ello el respeto por el rito, la costumbre y la naturaleza del lugar y del conjunto de condicionantes que subyacen bajo la motivación del encargo de la obra.

Distributio significa la buena y correcta administración de la economía asignada al proyecto, algo que para Vitruvio tiene notable importancia y peso en la concepción del trabajo del arquitecto; pues a éste le compete la ejecución de un presupuesto ajustado y adecuado a la obra y que en él quede garantizada y quepa adecuadamente la idea motora y germinal de su arquitectura.

Dicho pues todo esto, y atendiendo sistemáticamente a estos seis principios intelectuales de lo teórico del objeto arquitectónico, podemos tomando a la inversa las nociones de Vitruvio estableces un procedimiento metodológico que resuma la labor del arquitecto.

En primer lugar, tras la recepción del encargo de la obra a proyectar y después a ejecutar, la labor del arquitecto arranca atendiendo a un ajustado presupuesto y a una buena distribución de la administración del gasto y de los recursos a emplear. Es decir, es precisa una organización de la economía del proyecto para determinar la profundidad de su alcance y las metas perseguidas.

En segundo lugar hay que atender al decoro, es decir a la función, a la costumbre y a los ritos propios y característicos del lugar, entendiendo éste no ya sólo como un medio físico en el que implantar la arquitectura, sino también como algo abstracto que condiciona su adecuado funcionamiento y su persistencia a lo largo del tiempo. Con ello también Vitruvio abunda en que la forma tiene que seguir a la función y por ende constantemente insiste en la adecuación de los espacios, sus materiales, sus medidas, su ornamento, etc. Todo ello además motivado por cuestiones paralelas que condicionan todo tales como el rango social y/o el poder económico del encargante.

En tercer lugar, y tras la evaluación de los dos pasos anteriores, comienza la actividad intelectual y creadora del arquitecto determinando la regla de la simetría o sistemas de proporciones para que con ello se puedan dar los primeros esquemas de la traza de la planta y así conocer magnitudes que a posteriori puedan ir sufriendo modificaciones que hagan aparecer la euritmia del proyecto. Aquí pues, el arquitecto plantea la concepción general de la belleza del conjunto, generando correspondencias geométricas y/o matemáticas entre volúmenes y superficies, entre masas y vacíos, entre luces y penumbras, que den como consecuencia planos de alzados y/o secciones del edificio.

Con ello pues se alcanza, en cuarto lugar, la disposición del contenido del documento del proyecto. Es decir, es momento de elaborar un conjunto de dibujos y convencionalismos gráficos en los que se pueda interpretar, aunque aún de forma codificada, la obra proyectada. En este punto sólo el arquitecto es capaz de visualizar y comprender el resultado final construido, aunque sin embargo, con ello la idea deja de estar en la mente del arquitecto para convivir, a través del papel, con otros agentes intervinientes en el proceso constructivo.

Al mismo tiempo que se va completando el proyecto, el arquitecto va organizando y elaborando los detalles de la compositio; es decir, el diseño, las medidas y proporciones de las partes y detalles arquitectónicos, donde la columna, como entidad moduladora básica juega un papel fundamental.

Y finalmente la última parte del trabajo teórico del arquitecto que precede al comienzo de las obras, es la conmensuración u ordinatio. Se trata pues de pasar el proyecto a medidas físicas concretas y acotadas a través del empleo de los módulos, para que de esta forma puedan entender los oficiales y capataces de obra el conjunto de tareas a desarrollar. 
Todo esto conforma la ratiocinatio o labor intelectual del arquitecto, que finalmente y a modo de resumen debe quedar plasmada en planos de planta (ichnographia), alzados (orthographia) y perpectivas (scenographia), en la que puede apreciarse todo el resultado final con absoluto detalle y en el que los peritos y técnicos cualificados de las labores de obra pueden leer sus atribuciones y recibir las instrucciones sobre las funciones a realizar de forma inequívoca y precisa.

A partir de aquí comienza la dirección de obra o fabrica, cuya labor no es menos interesante ni compleja, pero que se sale del marco de trabajo de esta investigación debido a la singularidad y a la particularidad histórica del objeto arquitectónico de las ruinas de la Iglesia de Santa María de Cazorla.

\section{Análisis metrológico y coordinación modular de las ruinas de la Iglesia de Santa María de Cazorla.}

A la vista de lo que se ha comentado anteriormente, es fácil deducir que el arquitecto proyectista de la traza de la Iglesia de Santa María de Cazorla tendría en cuenta, dadas las condiciones de su tiempo, un conjunto de criterios geométricos y matemáticos que regirían la composición espacial y constructiva del edificio.

Ello lo condiciona todo y modula todas las partes del supuesto edificio; para que todo el objeto arquitectónico tenga un criterio de continuidad que valida la percepción de un único espacio, aun cuando fueran diversos arquitectos los que intervinieran o incluso cuando se superpusieran distintos estilos arquitectónicos, fruto de la dilatación del proceso constructivo en el tiempo.

Este análisis permitirá pues interpretar el concepto espacial del hipotético edificio ideado por el arquitecto; es decir, permitirá tener una aproximación conceptual al principio vitruviano de la ratiocinatio con la que se originó el templo.

El estado en el que actualmente se encuentran las ruinas es suficiente como para considerar concluidas el conjunto de directrices previas a la puesta en obra del concepto del edificio. Por lo tanto a partir de la observación y puesta en común de los diferentes elementos existentes, aunque inconclusos de la edificación, la sistemática propuesta por Vitruvio y ampliada posteriormente por los múltiples tratados de arquitectura ya existentes en el momento en el que se da la traza del edificio, nos posibilita, haciendo uso de una sistemática deductiva, ir completando los trazos mínimos para cerrar el concepto espacial y volumétrico de la obra.

Partiendo de un estudio comparativo de la geometría de edificios coetáneos y de similares características, incluso del mismo autor al que se atribuye la traza de la iglesia de Cazorla, Andrés de Vandelvira, podemos fundamentar un análisis que con cierto rigor, nos ayude a establecer las relaciones métricas y espaciales que existen entre los restos aún conservados y recientemente restaurados, y entre todo el conjunto de soluciones arquitectónicas de aquellos espacios inacabados en la obra. Es decir, las matemáticas y la geometría métrica, nos pueden servir para reconstruir de un modo virtual los fragmentos inexistentes de la obra, basándonos en un sistema deductivo fundado en comparaciones geométricas, espaciales y proporcionales respecto de edificios que a ciencia cierta se reconocen con idénticas cualidades y con similitudes inexpugnables, tal y como se expuso anteriormente.

De este análisis pues es posible despejar incógnitas perdidas que actúan en pasos intermedios fundamentales para determinar el resultado final de la obra arquitectónica, y con ello la percepción y la apariencia no ya solo formal, sino también funcional que habría tenido el templo. Es pues, que haciendo uso de las reglas de la symmetria, y siguiendo las indicaciones de la tratadística general ${ }^{15}$, podemos habilitar el todas aquellas herramientas

${ }^{15}$ No es preciso ceñirse al contenido de un documento (tratado arquitectónico) concreto para considerar las directrices de diseño y de control formal y espacial que habrían condicionado la labor del arquitecto. Ello se debe a que para nuestra hipótesis de trabajo, igualmente habrían sido válidas unas u otras, pues la idea de estudio se materializa sobre lo abstracto y no tanto sobre cuestiones de detalle. Además, es importante considerar que el proceso de ejecución de las obras probablemente habría abarcado muchas décadas, donde los ideales y los principios motores del encargo original seguramente habrían sufrido grandes modificaciones, que en algunos 
conceptuales y proyectuales previas a la fábrica del elemento. Con ello se llegaría a la obtención del contenido de la información intelectual, pero también proyectual y ejecutiva, de la dispositio que el arquitecto proyectista, Andrés de Vandelvira en nuestro caso, habría considerado para nuestra iglesia.

No es baladí este asunto, pues aun cuando algunas dimensiones pudieran obtenerse partiendo de caminos geométricos diferentes, de la relación de grafismos obtenidos podemos extraer ideas concluyentes a propósito del control espacial del recinto sacro; esto es, podemos reflejar la totalidad de los parámetros de la eurythmia que el arquitecto pudo considerar al recibir el encargo.

Pero es que además, tal y como los grandes autores abogan, sólo el arquitecto podía ver en su mente la obra terminada, y si con este estudio podemos adentrarnos, aunque al menos sea de forma tangencial, en el intelecto del proyectista, podremos robarle ideas y visiones, que aplicadas al uso de las técnicas contemporáneas que ahora manejamos, nos permitan tener la misma imagen que aquél visionó.

La conmensuración y el tratamiento metrológico de los vestigios existentes nos definirán los tamaños comparativos y/o modulares de todas aquellas piezas perdidas necesarias para completar el puzle al que nos enfrentamos. El tratamiento que se requiere de esta información, de haberse obtenido por aplicación estrictamente directa de lo anteriormente enunciado, sería mínimo de cara a conseguir la pretensión final de conocer el contenido global de la idea del espacio arquitectónico ${ }^{16}$.

Sin embargo también es oportuno matizar que no se puede establecer un análisis generalista atendiendo a cuestiones dimensionales que abarquen de una vez la totalidad de las ruinas, pues precisamente por tratarse de ruinas, $\mathrm{y}$ al encontrarnos demasiados fragmentos inacabados, podríamos perder de vista quizá algunas soluciones estilísticas u ocurrencia plásticas y formales que pudieron haber sucedido en momentos muy puntuales del proceso constructivo; tal y como son ciertos anexos volumétricos que aparecen en algunos puntos de la obra y de los que hablaremos más adelante. Es cierto que estas cuestiones no son del todo relevantes en la obra que no ocupa, pues a mi criterio, no tienen peso suficientemente consistente como para considerarlas importantes de cara a experimentar desvíos con respecto a la idea matriz del proyecto.

Dicho esto, atenderemos pues a la geometría y modulación de la obra desde lo general a lo particular y viceversa, para que de este modo, por comparación, podamos evitar errores y/o incongruencia dimensionales no tolerables.

Por lo tanto, a continuación, se detallan las relaciones existentes entre las diferentes definiciones geométricas de los distintos elementos arquitectónicos que aún hoy perduran en las ruinas de la iglesia de Santa María de Cazorla.

Para ello trabajaremos las secuencias espaciales y las lecturas métricas de las definiciones gráficas del edificio a través de su lectura en planta (ichnographía), alzado (orthographia) y perspectiva (scenographia).

Determinación del módulo. Unidad básica compositiva.

Como ya sabemos el comienzo de la labor de la parte teórica del proceso proyectual arranca con la ordinatio a través de la disposición de las unidades de medida mínimas, que

casos incluso lo habrían llevado a polos opuestos. A este respecto sólo nos interesa lo puramente empírico, lo metodológico y lo procedimental, por encima del resultado final con el que la obra se nos hubiera mostrado de haber sido finalmente concluida.

16 Ruiz de la Rosa ilustra el panorama fundamental y los aspectos generales básicos de la idea del espacio arquitectónico en el Renacimiento Andaluz. Si bien habla de Andrés de Vandelvira y alude a varios lugares de la geografía giennense para abordar la obra de este arquitecto, no hace mención alguna de su trabajo en Cazorla; pero su exposición arroja luz sobre los modos de hacer y la forma en que la labor del arquitecto alcaraceño se materializa. Podemos considerarlos válidos también para esta obra, pues parece que la autoría de Vandelvira ya ha quedado demostrada y por lo tanto marcan el horizonte de aquello que se puede esperar conseguir en el estudio analítico que nos ocupa, toda vez que, tal y como Ruiz de la Rosa describe, garantizaría la pureza de una arquitectura muy depurada e intelectualmente bien articulada. 


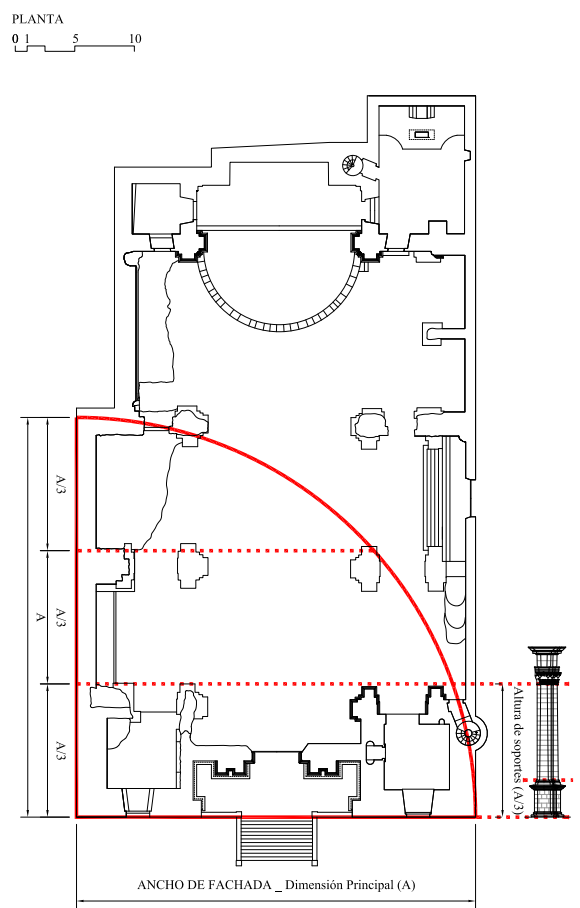

Fig. 1. Análisis metrológico y coordinación modular. Determinación del módulo principal de las ruinas de la Iglesia de Santa María de Cazorla. CJesús Estepa Rubio.

consideradas como módulos, organizan las relaciones de los distintos elementos y cualifican la disposición de los espacios y las razones proporcionales de todos y cada uno de ellos.

Para Vitruvio el módulo ha de surgir de aquellas partes más relevantes del edificio, tal y como es la anchura de la fachada principal del templo. Conocida esta dimensión podemos despejar el valor de la altura de una columna intermedia de cualquier pórtico pues debería coincidir con el valor de $1 / 3$ de la dimensión considerada de partida.

Efectivamente el valor de la altura de las columnas, atendiendo casi de forma imperativa a los mandatos del orden clásico, tiene una longitud igual al valor de un tercio del ancho de la fachada, lo que configura para el espacio interior del templo una proporción de sobriedad y elegancia estilística muy característica de las iglesias del Renacimiento andaluz.

Es sin embargo singular cómo la altura de la columna se limita al arranque del capitel, pues en la medida obtenida para la coordinación de las dimensiones verticales, no considera la dimensión de este elemento; es decir, la medida reguladora de los soportes no tiene en consideración el alto que incrementa la disposición del capitel. Ello se puede explicar atendiendo fundamentalmente a dos hipótesis diferentes.

En primer lugar quizá ello es debido a que el proyectista pensó en una variante al capitel definido por el estilo corintio clásico, tal y como vemos en los existentes en las ruinas de la Iglesia de Santa María de Cazorla, donde el formato genérico de hojas de acanto y volutas se sustituye por un diseño con motivos antropomórficos. Ello indujo al arquitecto a evaluar los valores de modulación sin considerar este elemento constructivo, dando así libertad creativa al tallista, para que la variedad y la heterogenia formal ${ }^{17}$ fueran aspectos diferenciadores de la arquitectura y el ornado de esta obra.

${ }^{17}$ Son varios los ejemplos de la arquitectura renacentista en la provincia de Jaén donde los capiteles aparecen modulados con proporciones y varianzas métricas notables dentro de un mismo edificio. Uno de los casos más ilustrativos es el de la iglesia parroquial de la Inmaculada Concepción de Huelma, donde algunos capiteles de orden corintio se comprimen en la dirección de su vertical generando una solución extraña e incluso amorfa. No es posible determinar a ciencia cierta cuales pueden ser las causas que motivan tal diseño, y probablemente no sean decisiones tomadas a priori por el proyectista, pero por otro lado es cierto que la distorsión visual de 


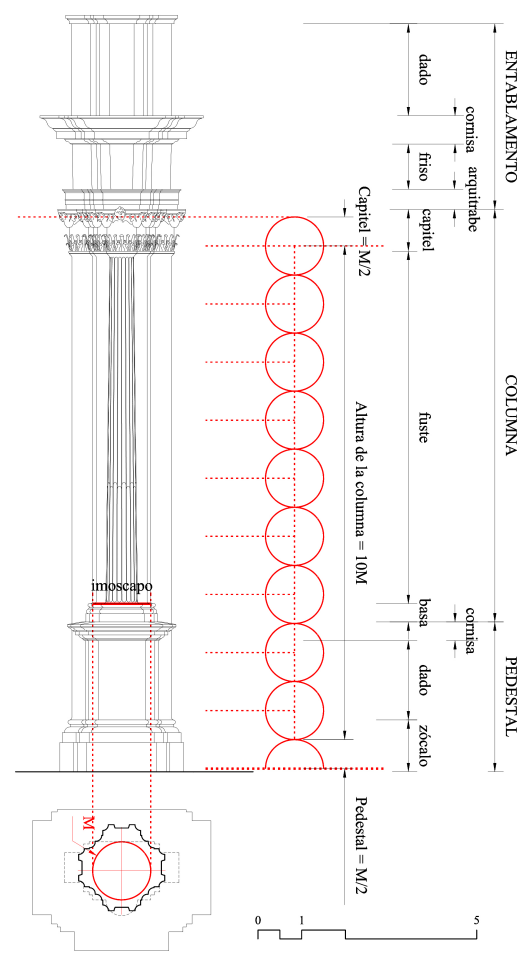

Fig. 2. Análisis metrológico y coordinación modular. Compartimentación y subdivisiones del soporte tipo de las ruinas de la Iglesia de Santa María de Cazorla. (C) Jesús Estepa Rubio.

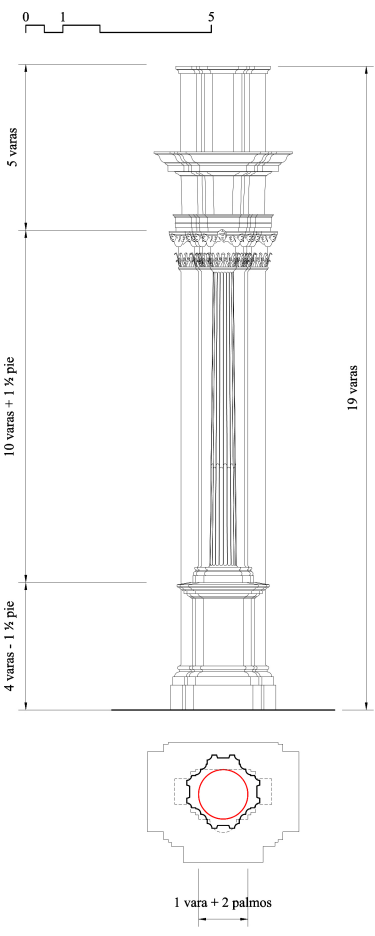

Fig. 3. Análisis metrológico y coordinación modular. Medidas del soporte tipo de las ruinas de la Iglesia de Santa María de Cazorla. (C) Jesús Estepa Rubio.

Por otro lado, existe la posibilidad de que en el trazado modular el arquitecto tomara tal decisión de manera intencionada, a los efectos de aumentar la percepción de verticalidad en el espacio interior del templo. Con ello se consigue que el arranque de las bóvedas vaídas se desplace ligeramente hacia arriba y con ello aumente el ángulo de percepción de su intradós. Este recurso es muy utilizado, introduciendo además otros elementos constructivos diferentes entre la cornisa del entablamento y el arranque de la montea, para empujar hacia arriba la clave de la bóveda vaída y minimizar con ello la pérdida de superficie visual en los arranques de los arcos torales intermedios.

Para el trazado geométrico de los elementos del soporte, se ha dispuesto éste de forma que su longitud total alcanza $91 / 2$ vece el valor del diámetro del fuste tomado en su imoscapo y 10 veces este valor contando la dimensión del arquitrabe. Este desvío de media unidad está justificado con la explicación anterior referida al tamaño del capitel. En cualquier caso, la dimensión total del soporte tipo del templo está muy bien ajustada a las directrices de la regla romana, manteniendo por tanto el principio de esbeltez que caracteriza al orden corintio.

La medida del módulo de la iglesia se concreta a escala natural en $1^{\prime} 33 \mathrm{~m}$, que traducido a las dimensiones propias de la arquitectura clásica equivale a 1 vara y 2 palmos. Es curioso detectar que la dimensión del soporte no es fortuita, sino que su magnitud entra dentro del conjunto numérico de las armonías musicales, pues tiene proporción sesquitercia $4 / 3$. Y con ello la longitud total asignada de 9 diámetros para la medida total del soporte (sin contar el zócalo) viene a mostrarnos la coherencia formal y dimensional de la solución adoptada, ajustándose a la serie numérica sesquitercia 9, 12, 16.

Conocido este dato pues tenemos pues la información dimensional básica para deducir, a través de las relaciones de proporcionalidad detectadas, cada una de las medidas de las

la proyección perspectiva de tales elementos propicia una corrección geométrica que viene a homogeneizar el aspecto del conjunto. 

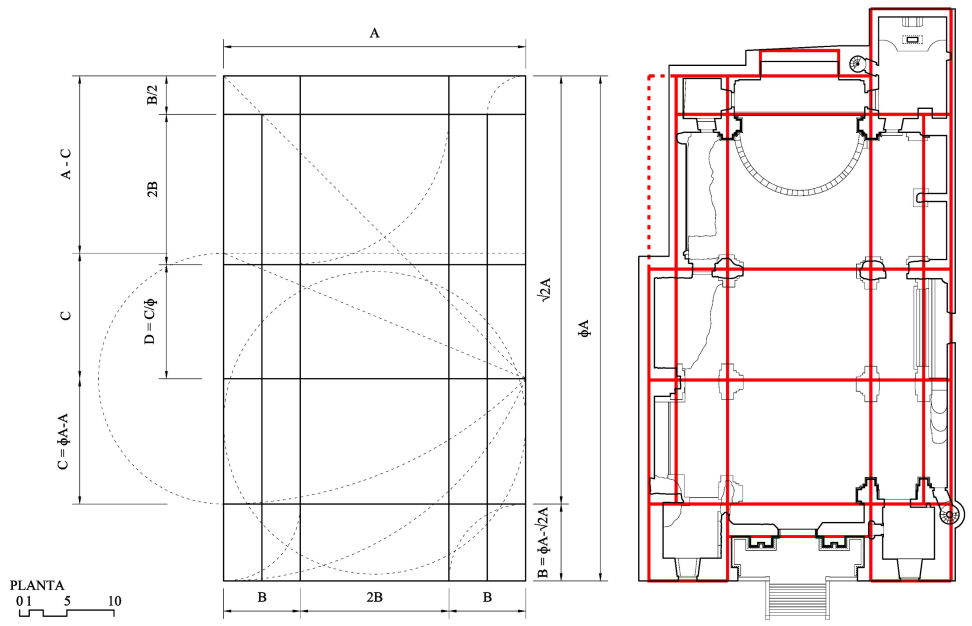

Fig. 4. Análisis de proporciones. Espacios de compensación de superficies de la planta de las ruinas de la Iglesia de Santa María de Cazorla. C Jesús Estepa Rubio.

diferentes partes de la iglesia. Con ello pues se genera todo un set de herramientas dimensionales y formales que nos pueden permitir construir la totalidad de la geometría de las ruinas y completar los restos inexistentes, despejando las incógnitas métricas intermedias ${ }^{18}$.

A partir de esta medida se puede reconstruir la totalidad de los espacios ahora inconexos de la iglesia, y comparando los resultados con la métrica y las dimensiones de las iglesias de la provincia de Jaén ejecutadas en periodos semejantes, sería posible verificar el grado de exactitud y la precisión de la información obtenida.

Medidas del espacio interior del templo.

Sólo cuando se tiene conocimiento del origen modulador y del patrón compositivo del conjunto de medidas que podemos leer a la vista de la geometría del edificio, tiene sentido analizar el valor numérico de las dimensiones detectadas.

No es fácil determinar si en la forma en la que el proyectista concibió el diseño de la obra, el control espacial de su contenido se realizó desde lo general a o particular, o si al contrario, la totalidad de la propuesta arquitectónica surge como adición de sucesivas propuestas de diseño independientes para cada una de las diferentes estructuras formales y espaciales que son imprescindibles para la correcta articulación de sus requerimientos funcionales.

Para la primera hipótesis la forma de trabajo se fundamenta en que el arquitecto pudo dar una traza de perímetros envolventes generales, y después introduciría particiones y subdivisiones que irían loteando los espacios de acuerdo con las exigencias del programa funcional requerido. Todas y cada una de estas particiones deberían seguir un esquema

18 La coordinación modular y el conocimiento de la unidad de medida básica del edificio es clave para entender la forma en la que se concibe el diseño arquitectónico que ha de dar respuesta a un encargo concreto y específico, que atiende tanto a condicionantes propios del promotor como a otros singulares e inherentes al lugar en el que se implanta la obra. Sin embargo, las relaciones de proporcionalidad dadas para solucionar los problemas métricos y espaciales tienen, no en pocas ocasiones, que sufrir ligeras correcciones y alteraciones que posibiliten adaptar la idea arquitectónica a una realidad material, física y constructiva. Ello es lo que sucede en el caso que nos ocupa, pues la singular posición del emplazamiento elegido para la Iglesia se Santa María de Cazorla, fuerza modificaciones numéricas mayormente por la intersección de la caja mural del templo con la ladera de la Peña de los Halcones.

Es aquí donde entra en juego valorar las semejanzas, teniendo siempre en el punto de vista el valor numérico de la unidad básica de coordinación modular, con otras edificaciones equivalentes, bien por su escala, su temporalidad, e incluso por la autoría del mismo arquitecto. Y con ello se puede por lo tanto estimar todo el rango de valores numéricos no conocidos que son necesarios para completar el esquema métrico y el organigrama proporcional que controla y que da orden al espacio interior, pero también el aspecto y la apariencia formal exterior, que categoriza al edificio estudiado. 


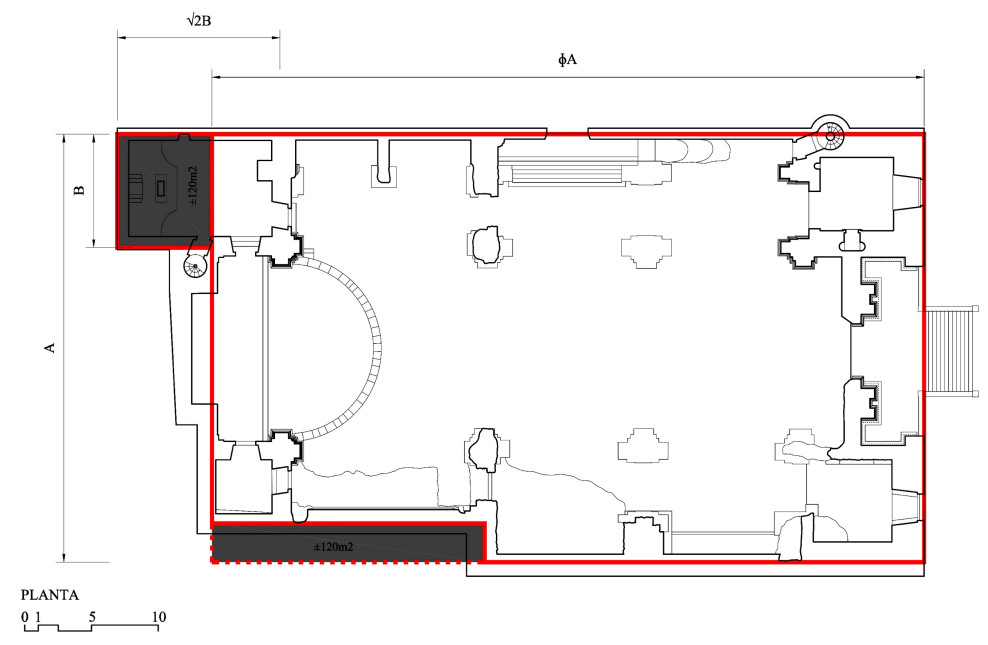

Fig. 5. Análisis metrológico y coordinación modular.

Traza de la planta de las ruinas de la Iglesia de Santa María de Cazorla. CJesús Estepa Rubio.

organizativo y unas relaciones de proporcionalidad en las que se mantenga la lógica del proyecto conservando inalterada la idea básica y substancial del germen de trabajo.

La otra hipótesis abogaría por un procedimiento de trabajo justamente inverso. En este caso el proyectista trabajaría conjuntando todo un listado de espacios proporcionados y dimensionados de forma autónoma e independiente, que habría de casar y adaptar cada uno con sus contiguos y con la totalidad del conjunto, salvando las distorsiones y dificultades impuestas por los condicionantes externos introducidos por el propio emplazamiento y por los avatares técnicos y constructivos que hubieran de aparecer a lo largo del proceso.

Sea cual fuere el mecanismo de trabajo ${ }^{19}$, en ambos casos el control espacial y la conexión métrica entre las partes nacidas por la coordinación modular de los elementos arquitectónicos, habría generado idénticos resultados.

No obstante, parece oportuno pensar en un planteamiento deductivo, pues es la mejor manera de ir obteniendo datos fiables que no condicionen los pasos posteriores. También sería lógico pensar que Vandelvira pudo dar la traza atendiendo sólo a los condicionantes primordiales $^{20}$ del lugar elegido para la obra, y que a medida que fueron avanzando los trabajos de construcción, ciertas decisiones de control pudieron ser corregidas.

${ }^{19}$ En este apartado de trabajo quizás no resulte demasiado relevante determinar de forma tajante si el planteamiento de diseño de los espacios de proyecto avanza desde lo general a lo particular o si por el contrario nace del detalle y el proyecto surge por acumulación de éstos; pues aún en este punto sólo interesa el resultado más que el camino seguido hasta llegar a él. Es decir, de momento el planteamiento de estudio se centra sólo en cuestiones métricas y analíticas derivadas de las dimensiones arqueológicas, sin abundar más allá de lo que de ellas percibidos; esto es, aún no se plantea una acción propositiva sino sólo contemplativa, diferencia que radica entre la labor del análisis patrimonial desde la óptica arqueológica frente a la arquitectónica.

Sin embargo, debido al objetivo final pretendido en este estudio, para recrear y reconstruir el espacio de la iglesia, es importante tenerlo en cuenta, pues probablemente ello condiciona directamente al procedimiento constructivo y a la puesta en obra de la fábrica y con ello a los vestigios que de ella nos llegan hasta hoy.

No cabe duda alguna de que la ejecución de las obras tuvo que alterar los planteamientos métricos y las conexiones proporcionales y moduladoras de los espacios y/o elementos constructivos ideados para el templo; por ello plantearnos cual puedo ser el criterio de organización del trabajo de diseño para avanzar en las decisiones tomadas por el proyectista, tiene notable importancia a los efectos de conseguir una visualización espacial, geométrica, formal, y en definitiva verdaderamente arquitectónica, que se adecúe de forma verosímil y eficaz con las ruinas de la iglesia.

${ }^{20}$ No podemos olvidar que la singularidad de la obra de la Iglesia de Santa María de Cazorla nace de dos condicionante físicos de relevante peso específico. En primer lugar la posición contrapuesta a la ladera de la Peña de Los Halcones que obliga a modificar el perímetro de la caja mural; y por otro lado, el extraordinario condicionante de cimentar la iglesia sobre la cuenca del Río Cerezuelo, dando como resultado un edificio nada común en el proceder constructivo de la época y desde luego irrepetible a lo largo y ancho de la geografía de la 
Para la correcta definición de los aspectos métricos y por ende geométricos del espacio interior del templo, lo más adecuado es atender a ellos por un lado en planta y por otro lado en sección, pues tal y como ya vimos atendiendo a las indicaciones de L. B. Alberti en su De re Aedificatoria, las dimensiones de los largos y anchos de los espacios son condicionadores para determinar las dimensiones en altura.

Medidas en planta.

La planta se organiza a partir de un gran rectángulo que da fachada a la Plaza de Santa María y a la Calle de La Hoz con dimensiones totales extremas de 36 1/2 varas y 66 1/2 varas respectivamente. Tales medidas son las máximas existentes en tales paramentos tomadas desde las aristas de intersección de los planos de cada fachada con su fachada ortogonal colindante.

Sin embargo, la estructura organizadora y modular de la planta de la iglesia se rige a través de unas líneas moduladoras definidas a eje de muro, tal y como a continuación se detalla.

La planta se estructura a través de una caja mural que delimita su contorno con unas proporciones basadas en la sección áurea $\left(\phi=\frac{1+\sqrt{5}}{2}\right)$, que define un perímetro perfectamente limpio con las dimensiones de 54'24m de largo por 33'52m de ancho, que sólo se distorsionan mínimamente por la colocación de la sacristía y por la necesidad impuesta de salvar la morfología irregular de la Peña de los Halcones.

La sacristía se desliga de la geometría del conjunto excediendo el contorno máximo de sección áurea con una proporción independiente basada en la diagonal del cuadrado definido por su lado menor. Por lo tanto, tomando la proporción de $\sqrt{2}$ define un rectángulo cuyo lado mayor se orienta en el sentido de la perspectiva que tenemos a entrar en el recinto, generando una sensación de profundidad que magnifica el espacio.

La Peña de los Halcones quiebra la geometría total de la proporción áurea de la planta, haciendo que el muro perimetral se interrumpa en el lado del evangelio a partir del crucero. Es singular observar que el defecto de superficie que se quedaría en el área total de la planta definida en divina proporción, se compensa con el exceso de superficie que la sacristía rebasa respecto del rectángulo áureo; es decir, el quiebro de la Peña de los Halcones roba a la planta unos $120 \mathrm{~m} 2$, que es justamente lo que la sacristía rebasa el perímetro de la caja mural del recinto eclesiástico.

Así pues, aunque a primera vista pudiera parecer que la geometría en planta de la traza de la iglesia es irregular o caprichosa para adaptarse a las condiciones impuestas por el emplazamiento en el que se inserta, no es necesario profundizar demasiado para observar una plena armonía geométrica en la composición del ámbito recercado sobre el que se distribuirán los espacios de la iglesia.

Para la distribución interior de espacios, las relaciones geométricas se complican un poco más, aunque de igual modo, todas las proporciones se basarán en combinaciones matemáticas de las expresiones $\phi \cdot \mathrm{A}$ y $\sqrt{2} \mathrm{~A}$, siendo A la longitud del lado menor de la caja mural del recinto eclesiástico.

De este modo aparece el módulo con el que el arquitecto proporciona el sentido longitudinal de las naves de la iglesia, que adquiere un valor definido por la expresión matemática $\mathrm{B}=\phi \cdot \mathrm{A}-\sqrt{2} \mathrm{~A}$. Utilizando esta dimensión, y teniendo en cuenta la idea de proyecto del arquitecto, en la que la nave central es superior a las naves laterales, para magnificar y potenciar la perspectiva hacia el altar en el momento de la Eucaristía, se establece

provincia de Jaén. Ello sin duda hubo de ser un incentivo y un potente aliciente para Andrés de Vandelvira, cuya personalidad inquieta e investigadora, tal y como han probado Galera Andreu y Ruiz Calvente, seguramente le empujó a aceptar este encargo sin renunciar a estos obstáculos como parte característica y diferenciadora del proyecto. La impronta de Vandelvira y su capacidad investigadora nos induce a pensar en que a pesar de estas variables distorsionadoras introducidas al equilibrio numérico y compositivo de las proporciones establecidas para los componentes arquitectónicos de la iglesia, el arquitecto debió compensar los valores numéricos y geométricos para que en su conjunto todo finalmente se mantuviera en perfecta armonía. Es decir, lejos de ver estos condicionantes como un problema, seguramente fueron un reto y una gran oportunidad para hacer de este edificio algo único y especial, cosa que ya queda patente sólo considerando las ruinas de aquello que pudo ser. 


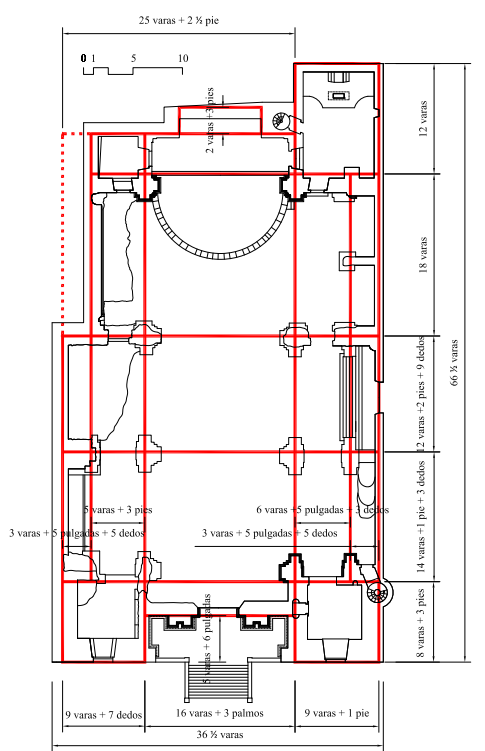

Fig. 6. Análisis de proporciones. Medidas de la planta de las ruinas de la Iglesia de Santa María de Cazorla. CJesús Estepa Rubio.

una duplicidad espacial en la nave central, de modo tal que el ancho de esta nave es igual al doble del ancho de las naves laterales; es decir, si las naves laterales adquieren una dimensión $\mathrm{B}$, la nave central adquiere una dimensión $2 \mathrm{~B}$.

La partición transversal de los espacios de las naves se origina imponiendo una doble condición: de un lado, un crucero de proporciones cuadradas $(2 \mathrm{~B} \times 2 \mathrm{~B})$, que probablemente se justifica con la intención proyectual de rematar la cubrición de tal espacio dignificándolo con una cúpula semiesférica; y de otro lado, unos pies que rematan la fachada de acceso al templo con dos torres también de proporciones cuadradas $(\mathrm{BxB})$, que generan protagonismo y fijación perspectiva en la escena urbana de la actuación de la plaza de Santa María de Cazorla.

Partiendo de esta premisa, ahora toca estudiar la posición de los pilares que subdividen longitudinalmente las naves de la iglesia. Los pilares se ubican en una posición que da lugar a intercolumnios basados en una proporción $\mathrm{C}=\phi \cdot \mathrm{A}-\mathrm{A}$, lo que origina espacios centrales rectangulares de dimensiones $\mathrm{BxC}$ similares a los que pueden encontrarse en las catedrales de Jaén y de Baeza. Tales recintos estarían cubiertos con bóvedas vaídas que partiendo de una geometría semiesférica dan lugar a secciones curvas diferentes para cada cara del rectángulo que originan sugerentes espacios muy característicos de la obra de Andrés de Vandelvira.

No obstante, en la planta podemos apreciar un desvío en la proporción del espacio central de la nave principal antes de que ésta acometa al crucero, y es que este espacio es ligeramente más estrecho que el que inmediatamente le precede de tal forma que en lugar de tener una proporción rectangular de $\mathrm{Cx} 2 \mathrm{~B}$ tendrá ahora una proporción $\mathrm{D} \times 2 \mathrm{~B}$. No puede saberse si se trata de una intención inicial del tracista o si por el contrario se debe a alguna forma de reestructuración de la geometría de la planta para adaptarla a algún tipo de condicionante físico o económico; pero sea como fuere, parece evidente que no se trata de una decisión tomada al azar o a estima, pues entre los valores $\mathrm{C}$ y D se establece una relación de divina proporción $\mathrm{C}=\phi \cdot \mathrm{D}$. Quizás el objeto de tal reducción longitudinal de la nave principal puede motivarse en la corrección perspectiva de los conos de visión que barren el espacio del crucero, de tal forma que con ello siempre éste es el elemento protagonista de todos los posibles enfoques perspectivos que se tracen en el interior de la iglesia.

De manera general es apreciable cómo todas las piezas de un puzle que a priori nos parece inconexo encajan teniendo en cuenta reglas matemáticas sencillas que se grafían a partir de 
un único módulo básico organizador de todo el conjunto, de manera global, y de cada una de las piezas que lo componen, de manera pormenorizada.

Vistas pues las relaciones de proporcionalidad y los condicionantes geométricos y dimensionales que el arquitecto tracista quiso establecer entre unos elementos y otros, así como en los mismos espacios del propio edificio, es ahora posible atender a dimensiones físicas concretas y de este modo conmensurar, de forma precisa y específica, los valores que hay que poner sobre el terreno para cumplir con los condicionante abstractos que acabamos de explicar. Por lo tanto, una vez que el diseño estaba claro y que todas las piezas de su creación formal encajaban adecuadamente atendiendo a sus imposiciones ideológicas y/o filosóficas, era momento de grafiar una planimetría sobre la que indicar y acotar de forma inequívoca y objetiva las medidas que los operarios de obra y canteros deberían dar a sus trabajos para cumplir con las expectativas integrales del diseño.

Así Andrés de Vandelvira pudo mandar que se organizase un templo a partir de dos grandes muros ortogonales entre sí de $361 / 2$ y 66 1 $\frac{1}{2}$ varas, sobre los que podría ir marcando los puntos que acotaran la colocación de los sucesivos hitos de referencia métrica.

El muro de fachada lo repartió en tres partes, donde la central es mayor que las dos laterales, para albergar en ella la portada principal y el acceso al templo por los pies desde el ámbito urbano más relevante, la Plaza de Santa María. Con ello utiliza por lo tanto el característico recurso de ingresar en el edificio y percibir en su acceso la máxima profundidad perspectiva posible, para que de esta manera el espectador quedara asombrado por la magnificencia y la contundencia del espacio sacro de la iglesia.

Esta parte central del muro principal de acceso tiene una dimensión algo mayor que 16 varas, por lo que restarían casi otras 18 varas que repartirá homogéneamente entre los segmentos de los costados laterales, para crear los arranques de dos torres de aproximadamente 9 varas de lado que vendrían a posicionar espacialmente en la escena urbana el concepto interior del templo, con una gran nave central y dos idénticas y de menor dimensión para los lados de la epístola y del evangelio.

Así el segmento de acceso vuelve a mantener el concepto de la armonía musical ${ }^{21}$ pues la fachada total tiene una dimensión de 2'25 veces el ancho de la crujía de acceso, es decir 36 varas son para las 16 varas del segmento central, una proporción basada en la razón 9/4, que es la armonía musical de dupla más tono.

El muro longitudinal, que se eleva verticalmente conformando la Calle de La Hoz, tiene una dimensión total de $66 \frac{1}{2}$ varas, pero recordemos que tal dimensión no es la correspondiente a la caja mural, pues ésta se ve incrementada debido al efecto de compensación del volumen de la sacristía por el defecto de metros producido en la planta como consecuencia de su posición medianera en la ladera de la Peña de Los Halcones.

A la dimensión de la sacristía corresponden 12 varas y en el segmento inmediatamente contiguo se ubica el crucero, con una dimensión de unas 18 varas, lo que viene a ser casi una cuarta parte de la dimensión total del muro, de modo tal que nuevamente se evidencian y se verifican las conmensuraciones características de las armonías musicales; esta vez con razón 4/1 que es, tal y como ya vimos, la que se denomina cuádrupla.

Igualmente sucede con la partición que define el intercolumnio siguiente, cuya dimensión guarda una relación de proporcionalidad de 1 '5 veces menor que la correspondiente al crucero, de modo que la relación entre ambas es la armonía musical 3/2, que se denomina sesquialtera. No parece extraño pensar que Andrés de Vandelvira introdujera

21 Todas las relaciones métricas y las razones armónicas y musicales que aparecen en la traza de las ruinas de la Iglesia de Santa María de Cazorla, vienen a demostrarnos que Andrés de Vandelvira no quedó al margen de las influencias neoplatónicas que caracterizan la arquitectura del Renacimiento. Y a pesar de que es bien sabido que Vandelvira no viajó a Italia, parece que esto no fue un impedimento para que su formación como arquitecto de primer nivel fuera completada con un éxito que su obra nos deja clara y evidentemente demostrado; pues no parece lógico que un simple cantero con conocimientos sólo adquiridos por decantación profesional y por hábitos tomados del trabajo cotidiano, alcanzase semejante sutileza y matices en cuanto a la precisión dimensional para conseguir armonías y controles geométricos que, de acuerdo con las creencias de la época, garantizaran el equilibrio y la perfección espacial, constructiva y funcional, toda vez que ponen todo ello en absoluta relación con las dimensiones del cuerpo humano. 


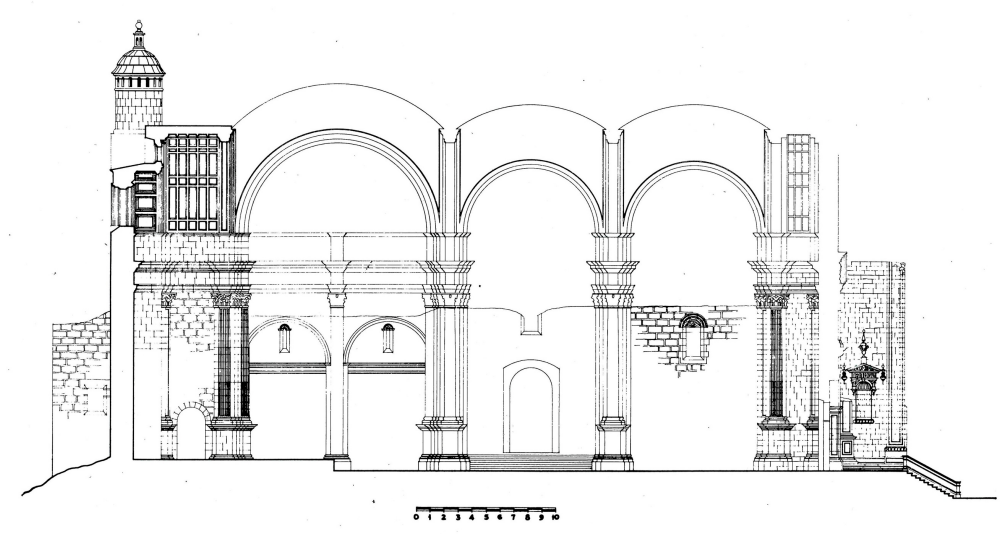

Fig. 7. Sección longitudinal de las ruinas de la Iglesia de Santa María de Cazorla. Dibujo de Ramiro de Moya publicado por Fernando Chueca Goitia.

conscientemente todas estas condiciones armónicas musicales, pues de hecho vuelve a repetirse la proporción sesquitercia en la siguiente partición, cuya dimensión de 12 pies representa respecto a su contigua, ya para el caso que nos ocupa la torre de fachada cuyo valor es prácticamente de 9 pies, la razón de $4 / 3$, que vemos que ya había sido utilizada anteriormente por Vandelvira a la hora de definir la dimensión del módulo unitario base.

Las naves laterales además son reducidas por la incorporación de capillas a todo su largo, tal y como sucede por ejemplo en la Catedral de la Asunción de Jaén, para que así la verticalidad de su espacio cubierto con bóvedas vaídas quede más pronunciada y a la vez se dote de mayor protagonismo a la nave central de la iglesia. Puede observarse pues que de las casi 9 varas totales de los espacios longitudinales laterales, tanto en la epístola como en el evangelio, 6 varas se dedican propiamente a la nave y 3 a las capillas laterales; por lo que nuevamente la relación de proporcionalidad entre unas y otras con respecto al total se apoyan en las razones $4 / 3$ o sesquitercia y $3 / 2$ o sesquialtera.

En conclusión, podemos decir que la totalidad de la planta y la traza geométrica moduladora y organizativa de los espacios de las ruinas de la Iglesia de Santa María de Cazorla, cumple perfectamente con todas las exigencias de control formal, geométrico y dimensional que imponen los tratados de arquitectura.

Ello se verifica en primer lugar comprobando que efectivamente todas las relaciones de proporcionalidad en abstracto, se relacionan a través de dimensiones inconmensurable tales como la sección áurea $\left(\phi=\frac{1+\sqrt{5}}{2}\right)$ o la diagonal $(\sqrt{2})$ generando todo un mecanismo de control del trazado de los espacios de la planta de la iglesia de acuerdo a los cánones de la normas clásicas.

Y por otro lado, una vez que el concepto del proyecto está concluido, y la ratiocinatio del encargo arquitectónico ha sido completada, también puede apreciarse como la conmensuración de los elementos constructivos atiende a armonías musicales que hacen del resultado un producto arquitectónico, no ya sólo de calidad, sino además completo y coherente con la filosofía y el ideal de su promotor, a propósito de los nuevos principios de vida que fundamentan a este nuevo humanismo renacido.

\section{Medidas en altura.}

Es evidente que todo el estudio de los aspectos vistos para la planta no puede concluir en ella, y por lo tanto todas las mismas limitaciones y condicionantes que sirvieron para dar su traza, ahora han de ser extensivas a la verticalidad del templo.

Si bien la geometría, la métrica y el control formal y espacial, a través de la coordinación modular, sirven en planta para cubrir necesidades mayormente funcionales; en la sección es 


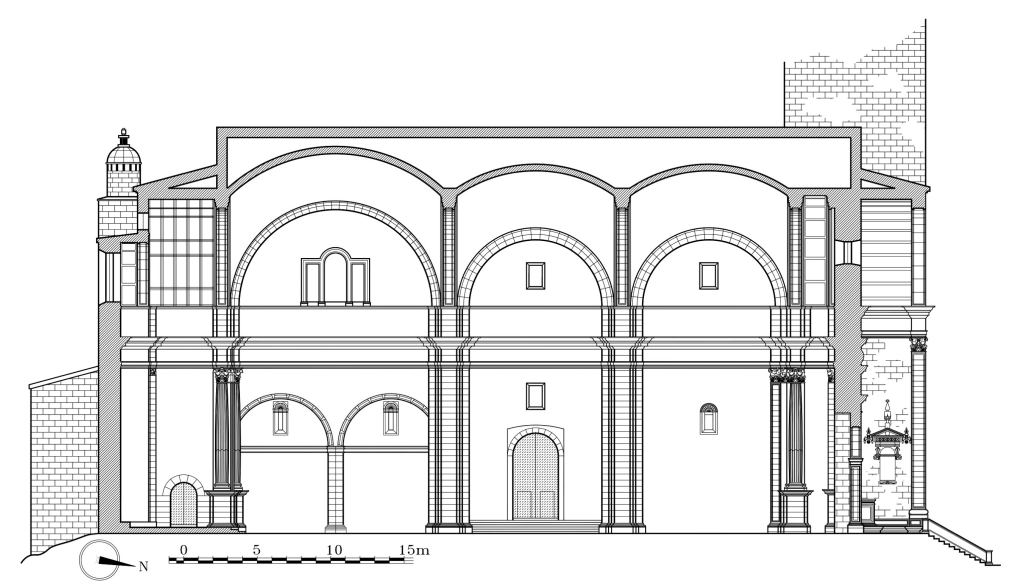

Fig. 7 bis. Hipótesis de sección longitudinal de las ruinas de la Iglesia de Santa María de Cazorla. Dibujo de Raya Moral, B. extraído de $\mathrm{La}$ arquitectura vandelviriana en la provincia de Jaén. Aportación a su estudio gráfico. Jaén: Diputación provincial de Jaén. Instituto de Estudios Giennenses. Fig.-65, p. 153 ISBN: 978-84-92876-52-5

donde verdaderamente se dignifica y se categoriza el espacio, pues su relevancia y su peso en la definición de la percepción perspectiva ${ }^{22}$ son muy contundentes.

De poco sirve organizar la traza de la planta perfectamente y sin descuidar un ápice las indicaciones de las composiciones del orden clásico, si después no se concatenan tales condicionantes para conseguir un resultado absolutamente completo, asunto que sólo se consigue a través del trabajo en sección.

Por lo tanto, es posible evaluar exactamente las mismas cuestiones que anteriormente hemos estudiado para la traza de la planta en cuanto a sus proporciones, dimensiones y coordinación modular, pero teniendo en cuenta pues los efectos de figuración y de teatralidad ${ }^{23}$ que la obra arquitectónica tendrá una vez que ésta sea procesada por el ojo humano a través de su percepción perspectiva.

Las alturas de los elementos sustentantes del edificio también deben estar expresadas en una relación matemática definida respecto al módulo básico que origina el proyecto.Y como ya hemos visto, todo se compone a partir de dos números no exactos $(\phi$ y $\sqrt{2})$, cuya dimensión sólo se puede determinar con precisión a través del dibujo, hecho que supone para la arquitectura un notable punto de interés y de aceptación.

La altura total de las naves es desconocida para nosotros puesto que la cubrición del templo jamás llegó a realizarse, pero a la vista de los elementos estructurales que perviven en las ruinas podemos determinar cuál debía haber sido su altura con absoluta exactitud.

22 La definición de los aspectos a considerar para la composición adecuada de la arquitectura acorde con los modos de hacer de los estilos clásicos, atendiendo a Vitruvio, sólo se produce a través de análisis y controles de razones de proporcionalidad basados en esquema geométricos sencillos y elementales ideados en planta y en sección. Pero es importante tener en cuenta que el hombre del Renacimiento piensa más allá aún, debido al aprendizaje y al dominio del control de las técnicas de puesta en perspectiva del espacio, que le permite evaluar otros asuntos a la hora de perfeccionar el diseño de los estilos clásicos mucho más completos que lo que demanda Vitruvio.

Aquí además entra en juego la teatralidad y la escenificación del espacio, pues la percepción del mismo categoriza sus dimensiones y con ello todas las relaciones dimensionales y métricas a las que éste es sometido a priori.

${ }_{23}$ Estepa Rubio, A. y Estepa Rubio, J., 2017. Figuración y teatralidad en las estructuras de comunicación vertical propuestas por los Vandelvira. Estudio formal y analitico del caracol de emperadores como caso teórico singular. Revista EGA. ISSN: 1133-6137. Valencia: Departamento de Expresión Gráfica Arquitectónica. Universidad Politécnica de Valencia. 


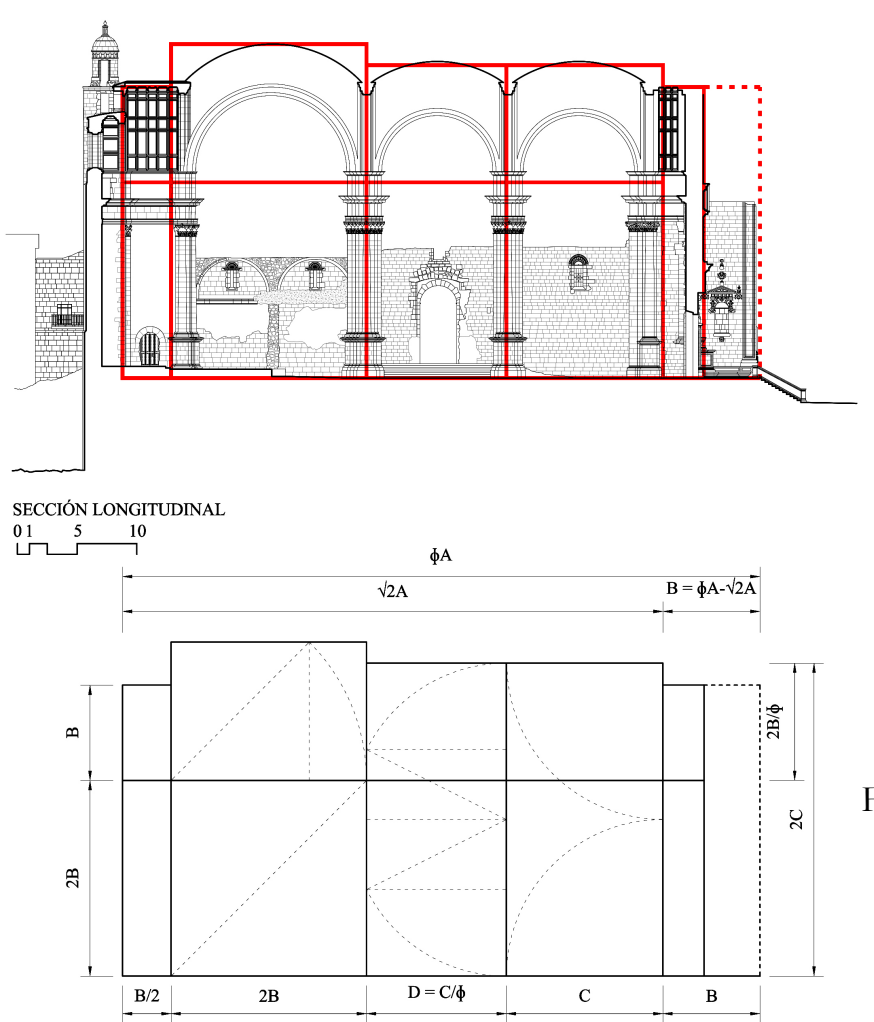

Fig. 8. Análisis metrológico y coordinación modular. Traza de la sección longitudinal de las ruinas de la Iglesia de Santa María de Cazorla. (C) Jesús Estepa Rubio.

El presbiterio mantiene intacta gran parte de los elementos necesarios que se requieren para tener conocimiento exacto de la totalidad de la altura del espacio interior del edificio, pues en este lugar conocemos con detalle las dimensiones de los pedestales, las columnas y el entablamento. Aquí el espacio se remata con un gran arco del triunfo sobre el que se dispone una serlina, muy al estilo de Andrés de Vandelvira. En el resto de las naves, sólo bastaría imaginar la cubrición de las techumbres para tener idea de la totalidad de la dimensión en altura de tales espacios, muy probablemente resueltos mediante la utilización de bóvedas vaídas propias de la época y del lugar en el que se emplaza la edificación, así como del gusto del autor que se le atribuye.

No en balde podemos encontrar algunas aproximaciones gráficas que pretenden completar parte de la sección del templo.

La primera de ellas se la debemos a Fernando Chueca Goitia, en cuyo libro sobre la obra de Andrés de Vandelvira ${ }^{24}$, no sólo atribuye la autoría de las ruinas de la Iglesia de Santa María de Cazorla al maestro alcaraceño, sino que en la descripción gráfica que hace de las ruinas, la sección longitudinal de las mismas no aparece dibujada tal y como ante nosotros se nos presenta, sino que Chueca atisba ciertos trazos que vienen a cerrar la cubrición del templo mediante el empleo de bóvedas vaídas. Cabe no obstante destacar que en el dibujo de Chueca sólo se atiende a la línea de sección del perímetro del espacio longitudinal del templo por el intradós, sin hacer más detalle o referencia alguna a la totalidad del elemento constructivo, esto es, sus grosores, su remate exterior en cubierta inclinada o en general cualquier otro detalle que venga a clarificar la idea de la totalidad del volumen del edificio en su conjunto. No obstante, el apunte de Chueca es bastante acertado y sin duda ello se debe a que de la información existente de las ruinas es totalmente posible despejar los datos necesarios para completar con rigor, cuanto menos la altura del espacio interior de la iglesia.

${ }^{24}$ Chueca Goitia, F., 1995. Andrés de Vandelvira, Arquitecto. Jaén: Riquelme y Vargas.Pp.295-298. 

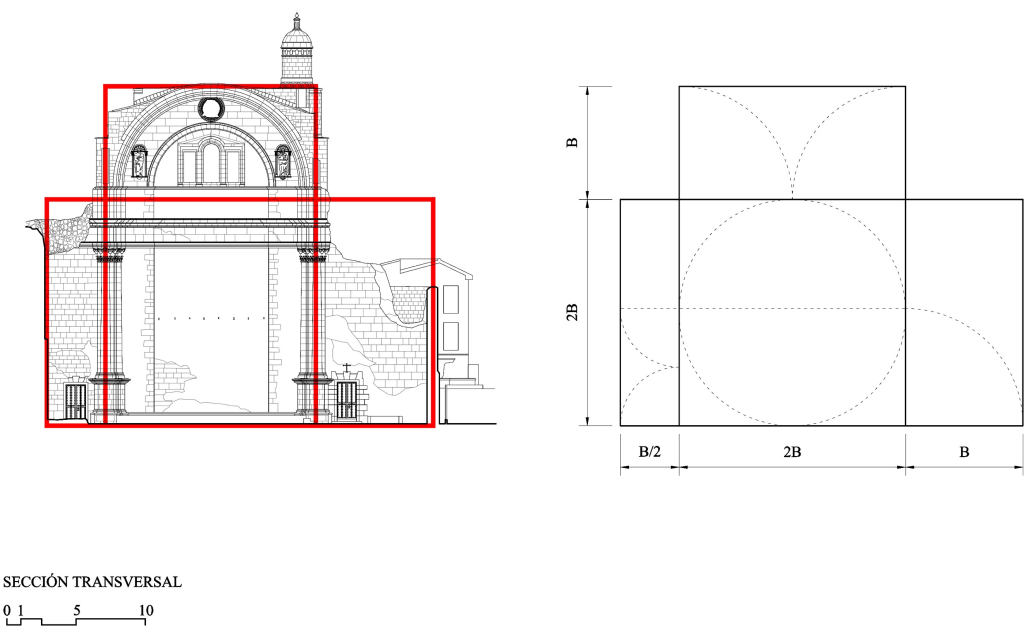

Fig. 9. Análisis de proporciones. Traza de la sección transversal de las ruinas de la Iglesia de Santa María de Cazorla. CJesús Estepa Rubio.

La otra es obra del Baltasar Raya Moral que aparece en su documento de atribuciones gráficas a la obra de Andrés de Vandelvira ${ }^{25}$. En esta publicación Raya Moral, probablemente basándose quizás en los dibujos de Fernando Chueca Goitia completa la sección longitudinal del templo, con excepción de las torres cuyo trazo sólo queda insinuado, pero añadiendo más información que el anterior, pues se lanza a determinar los grosores de los elementos constructivos así como a proponer una cubierta para la totalidad de la edificación, dando más o menos una idea general, no ya sólo del volumen interior del templo sino también del exterior del mismo. En este gráfico, la definición interior es bastante más detallada, avanzando detalles para los cerramientos laterales de la caja mural e incluso proponiendo determinados tipos de ventanas y huecos de apertura de luces.

No obstante, en lo que concierne a este apartado, sólo es interesante considerar lo referido al espacio interior del templo, pues a todas luces parece inviable el sistema de cubiertas propuesto por Raya Moral, no sólo por la extraña morfología de las mismas, sino por la aparición de determinados elementos constructivos de dudoso rigor, tales como los extraños hastiales frontales que aparecen por intersección de una cubierta a dos aguas con los faldones que cubren el arco de la entrada y el del presbiterio.

Volviendo al análisis de la preexistencia podemos continuar con el mismo criterio de trabajo con el que hemos analizado la traza de la planta.

La altura de las naves puede dividirse en dos tramos: la primera de ellas que nos la define la longitud total de los pilares del edificio, midiendo éstos desde los pedestales hasta las coronaciones de los capiteles; y la segunda de ellas que se deduce del radio de curvatura de las bóvedas vaídas que debían cubrir tales espacios y que se definen a partir de sus arcos torales, de los que todavía se conservan restos de sus arranques.

El primer tramo de la altura del templo tiene una dimensión igual que el ancho de la nave central y cuyo valor se ha cifrado como $2 \mathrm{~B}$, de tal forma que el espacio que determina el crucero adquiere una geometría cúbica. Las naves laterales adquieren de esta forma una proporción que las dota de una espacialidad esbelta y espigada, hecho que incide de manera directa en la percepción perspectiva de dichos espacios con profundidad y lejanía, mientras que la percepción de la nave central se acorta focalizando la atención del fiel hacia el altar.

${ }_{25}$ Raya Moral, B., 2015. La arquitectura vandelviriana en la provincia de Jaén. Aportación a su estudio gráfico. Jaén: Diputación provincial de Jaén. Instituto de Estudios Giennenses. ISBN: 978-84-92876-52-5 


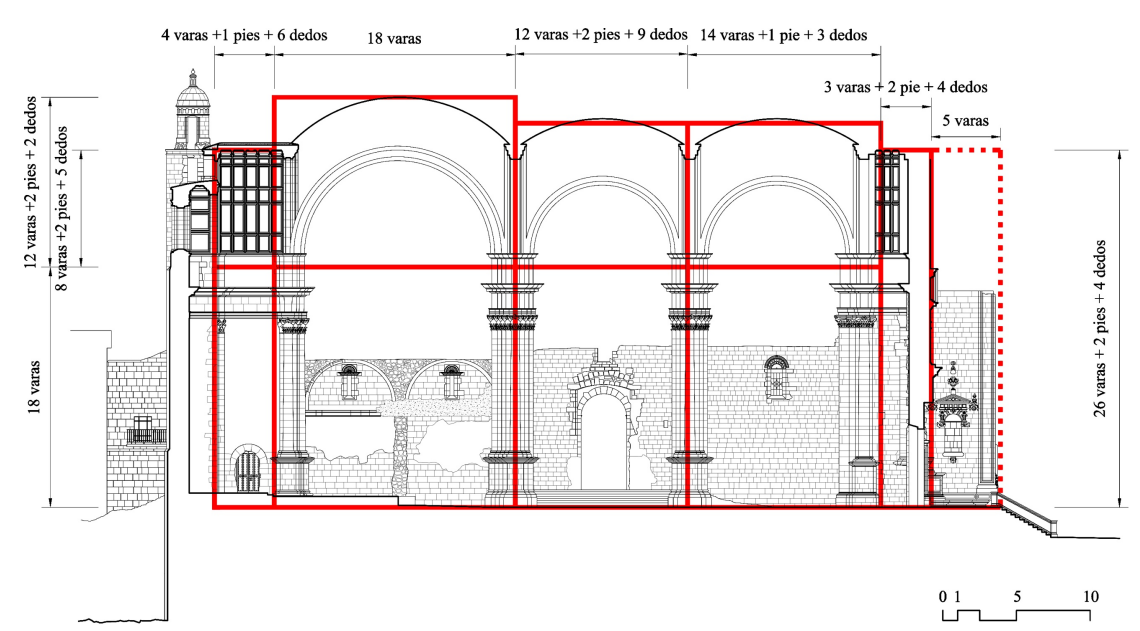

Fig. 10. Análisis de proporciones. Medidas de la sección longitudinal de las ruinas de la Iglesia de Santa María de Cazorla. C Jesús Estepa Rubio.

El segundo tramo tiene alturas variables en función del radio de la geometría esférica que origina las bóvedas vaídas que cubren tales espacios. Así pues el crucero tiene una altura $2 \mathrm{~B} / \sqrt{2}$ mientras que el resto de bóvedas tienen una altura de dimensión $2 \mathrm{~B} / \phi$.

Teniendo en cuenta por lo tanto ambos tramos, se establecen dos alturas diferenciadas para el análisis de las ruinas: la primera de ellas, correspondería al espacio del crucero, con una dimensión total de $2 \mathrm{~B}+2 \mathrm{~B} / \sqrt{2}$; y la segunda de ellas correspondería al resto de los espacios abovedados cuya dimensión sería $2 \mathrm{~B}+2 \mathrm{~B} / \phi$ y que equivale exactamente a $2 \mathrm{C}$. Sólo el presbiterio tendrá una altura diferente cuyo valor es $3 \mathrm{~B}$ originada al cubrirse tal espacio con una bóveda de medio cañón.

Cambiando ahora la visualización del plano de estudio $90^{\circ}$, podemos revisar la sección transversal del templo, donde analizaremos las condiciones del espacio que existen en el presbiterio, pues todas aquellas que se refieren a las naves de la iglesia se definen perfectamente en la sección longitudinal.

Como ya hemos deducido, la altura del presbiterio viene restringida por la del espacio del crucero, en proporción cuadrada y de ancho y alto igual a la dimensión $2 \mathrm{~B}$, que es la que a la vez condiciona los anchos de las naves de la epístola y del evangelio en proporciones de dupla y cuádrupla de su altura, manteniendo por lo tanto un ritmo constante y musical en armonía de razón de 2.

Raya Moral propone, para esta sección, una razón de proporciones muy similares a la expuesta, con la variante de considerar la altura en el intradós de la bóveda de medio cañón acasetonada del presbiterio, cuya razón de proporción, referida a la altura total medida desde el suelo al punto más alto del entablamento, se basa en $\sqrt{2}$.

Nuevamente observamos que todas las coordinaciones de espacios existentes en las ruinas pueden relacionarse también en altura a través de los dos mismos números que organizaban la planta, es decir, $\phi$ y $\sqrt{2}$, de forma tal que se mantiene un criterio unívoco para la composición espacial de todo el conjunto.

Visto esto, y al igual que se procedió con la traza de la planta, el arquitecto tiene por delante la labor ejecutiva de conmensurar las propuestas expuestas, por lo que ahora podemos ver el valor de todo ello en medidas reales que puedan ser llevadas a la obra de forma inequívoca.

Así pues resulta entonces que la altura máxima de la iglesia, tomada ésta en el crucero, es de unas $301 / 2$ varas, generando un espacio de dimensiones bastante considerables y con una potencia espacial que seguramente atendía al imperante tecnológico de buscar soluciones estructurales y constructivas inherentes a la grandilocuencia de su espacio. 


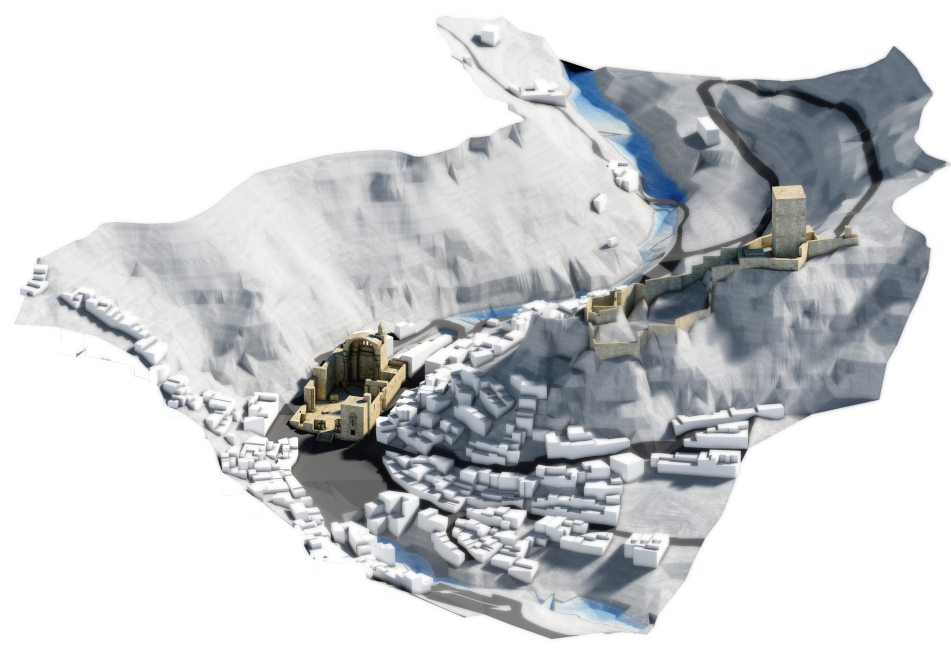

Fig. 11. Axonometría noroeste del ámbito urbano de las ruinas de la Iglesia de Santa María de Cazorla. (C) Jesús Estepa Rubio

Por otro lado el acceso al templo también tiene una dimensión contundente, con una altura total que podría rondar la 26 1/2 varas, es decir sólo 4 varas menor que el punto de mayor altura en el espacio interior del edificio. Finalmente tal diferencia se reparte homogéneamente para que la altura de las demás techumbres de la nave disten prácticamente sólo 2 varas hasta la altura del crucero.

Así pues, queda claro que nada en el edificio es aleatorio, y aunque dar con las combinaciones matemáticas aparentemente sea complejo, después éstas arrojan simplicidad y sencillez a la hora de determinar cómo deberían haberse sucedido los trabajos y los objetivos que con ellos debían cumplirse, para que de esta forma podamos tener, en la medida de lo posible, una idea clara de la espacialidad incluso de la formalización material de la propia iglesia.

Medidas de los alzados exteriores. La caja Mural.

Como primer germen de la traza de todo edificio, aparece un polígono inicial de replanteo de éste en el terreno, que acota la porción del espacio urbano que se va a transformar en algo nuevo a través de lo edificado y que delimita el espacio máximo capaz circunscrito a la obra.

Como hemos visto, todo arranca de un espacio conceptual que se engendra a partir de un rectángulo en divina proporción que engendra un espacio paralelepipédico de altura dada por la expresión matemática $\mathrm{H}=2 \mathrm{~A}(\phi-\sqrt{2})$, siendo $\mathrm{A}$ el valor del lado menor del rectángulo de la planta.

Tal y como ya se estudió en el análisis métrico de la planta, la geometría de la base sólo se distorsiona por la presencia de la Peña de Los Halcones, de modo tal que este elemento natural rompe la linealidad física del muro en el lado del evangelio forzando a que éste adquiera una nueva alineación desplazándose hacia el interior del templo una distancia igual a la profundidad de las capillas laterales que recorren los muros en sentido longitudinal. Es llamativo también observar cómo el grosor del muro casi llega a duplicarse en este lado con respecto al lado opuesto, quizás para tener que soportar los posibles empujes de la escorrentía de la Peña de los Halcones o quizás para soportar posibles impactos por desprendimientos o movimientos en la misma.

La impronta del edificio en la escena urbana es evidente y a ello contribuyen dos razones fundamentales, de un lado la propia escala que tiene el edificio, que le significa y lo dota de un protagonismo grandilocuente en comparación con el caserío menudo circundante; y por otro lado el hecho de que el edificio se emplace en mitad de un valle sobre la cuenca de un 


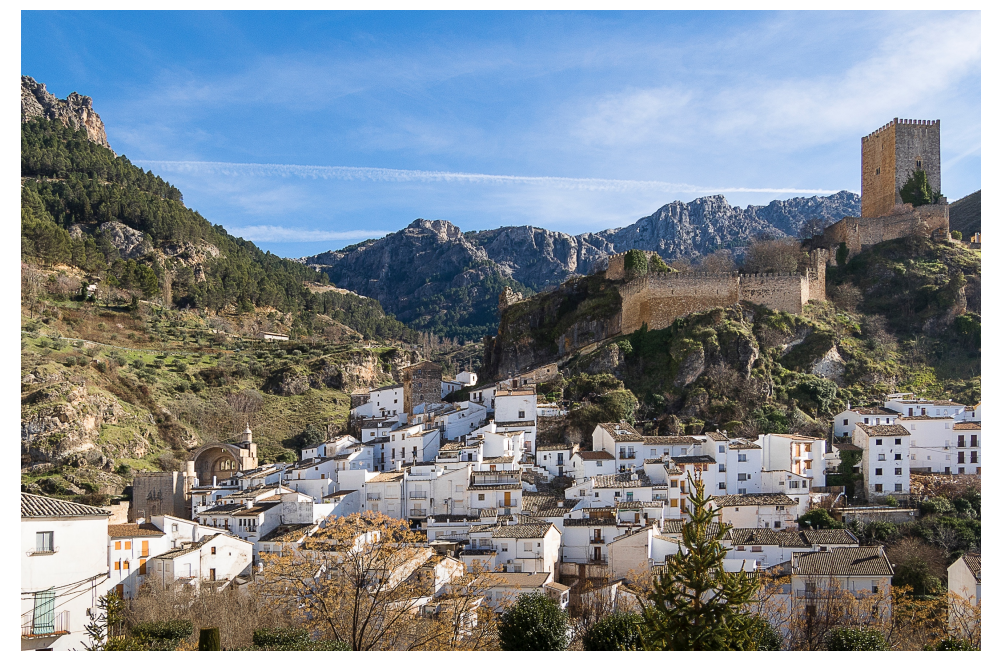

Fig. 12. Panorámica del estado actual de las ruinas en su entorno urbano. Vista lateral desde el tejido urbano. CFotografía de Francisco Javier Sánchez Castro

río, que hace necesaria una importante operación ingenieril que modifica el perfil natural del terreno para permitir que éste se asiente sobre él.

Si de manera abstracta analizamos la posición del volumen total del edificio en el medio natural-urbano, observamos que aunque la percepción espacial desde las calles está bastante bien moldeada, en una vista axonométrica descubrimos la enorme dificultad con la que el edificio contacta con el terreno; y a pesar de que el edificio es en tamaño muchísimo mayor que las edificaciones que lo rodean, desde casi la práctica totalidad de ellas puede tenerse un control visual de la iglesia, debido a que ésta se sitúa en una de las cotas inferiores del valle y en cambio no son pocas las viviendas que se reparten a todo lo largo del trazado vertical de la ladera.

La presencia del castillo es fundamental. Ambas piezas patrimoniales constituyen un conjunto que hace que éstas se relacionen hasta mantener una relación de necesidad recíproca: el castillo coronando la ladera, y la iglesia a los pies de la misma sobre el agua del río Cerezuelo. Este sistema vectorial organizado por ambos polos, crea un área propia y con identidad autónoma dentro del conjunto urbano de Cazorla, incluyendo las calles y los caminos, las casas y los espacios naturales salpicados por vegetación autóctona y espontánea y por su puesto los tránsitos de movimiento y de remanso que todos ellos generan, y que dotan a estos espacios de un sobresaliente interés turístico y cultural. La caja mural del edificio y su volumen capaz, generan pues un microespacio dentro del trazado urbano del casco histórico de Cazorla.

Este elemento arquitectónico funciona consecuentemente, no ya sólo como un elemento estructural y sustentante de los elementos de cubrición del edificio, ni sólo como un elemento geométrico delimitador de su forma y de su contenido, sino además como un límite abstracto que determina la separación entre lo público y lo privado, entre lo urbano y lo doméstico y que en determinados puntos se diluye para dilatar las líneas divisorias entre tales espacios, para posibilitar con ello diferentes tipos de relaciones sociales entre los usuarios el edificio y los transeúntes que fluctúan por los espacios urbanos en torno a la iglesia.

La caja mural se perfora por medio de los dos accesos que tiene el interior del templo, uno de ellos, por la calle de La Hoz, situado en el intercolumnio central de la nave lateral derecha y el otro a través de la plaza de Santa María, dando lugar a una pequeña plaza elevada sobre escalinata, flanqueada por ambas torres y que se origina como consecuencia del desplazamiento hacia el interior del templo de la portada de acceso, hasta hacer coincidir su eje estructural con el centro del cuadrado que define el interior de cada torre; esta placita 


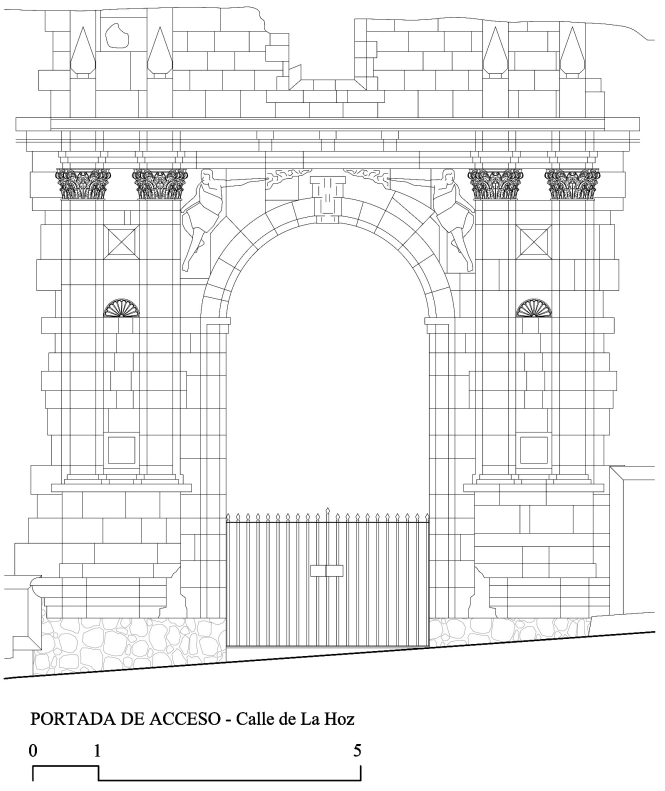

Fig. 13. Portada de la Iglesia de Santa María de Cazorla hacia calle de La Hoz: (C) Jesús Estepa Rubio sobre el de Pedro Salmerón Escobar.

elevada, permite una percepción visual de toda la plataforma de la plaza de Santa María, dominando así el espacio urbano residencial circundante.

El alzado que da a la calle de La Hoz, es sencillo y su sobriedad y serenidad hablan de un tipo de construcción que parece querer alcanzar ya una madurez intelectual en cuanto a la interpretación de las reglas del orden clásico. Se trata de una pared limpia, sin elementos estructurales que den muestra de lo que sucede en el interior del edificio y sólo las pequeñas ventanas rasgadas coronadas con tímpano avenerado interrumpen levemente su contundencia y su corporeidad pétrea. Todo el lienzo está encintado con un zócalo de sutil sencillez que agudiza la percepción lineal de toda la pared cuando ésta es vista desde la calle en la que se levanta el alzado. El acceso al templo por este costado se produce a través de un arco de medio punto situado a ras del muro y flanqueado por dobles pilastras que recogen un entablamento sobre el que se abre una ventana de la que quizás quede algo menos de la mitad de su altura.

Sólo hay un elemento que rompe la lógica compositiva y la modulación abstracta de la fachada, y no es otra cosa que una pequeña construcción cilíndrica que alberga en su interior una escalera de caracol en hélice circular desarrollable que permite el acceso a una supuesta entreplanta que seguramente tendría la iglesia y desde la cual se tendría acceso al interior de las torres para llegar al campanario.

El alzado que da a la plaza de Santa María es el acceso natural al templo y aunque su traza está sólo insinuada, sus proporciones dan cuenta de que seguramente, tal y como hacía Vandelvira y después sus sucesores, aprendiendo de Siloé, habría una gran portada con arco del triunfo que dignificara el acceso principal al edificio.

No se puede conocer a ciencia cierta cómo habría sido, pero Chueca nos descubre un dibujo de Ramiro de Moya en el que se plantean las líneas básicas para su posible composición, siguiendo esquemas muy similares a los de la portada lateral de la iglesia del Salvador de Úbeda, la iglesia parroquial de Sabiote o la de Mancha Real.

En estos casos se trata de un arco triunfal de medio punto flanqueado con dobles pilastras entre las que se insertan hornacinas y sobre el entablamento un pequeño retablo iconográfico sobre la advocación del templo que llega hasta los límites verticales de la caja mural del edificio; por encima de ello solamente un frontón triangular con que delimita la posición del eje de la nave central, focalizando para la escena urbana la posición del altar y del sagrario.

\section{Conclusiones.}

La ciudad de Cazorla difícilmente puede desconectarse de la impronta urbana y la condición patrimonial imprimida por las ruinas de la Iglesia de Santa María, hasta el punto 


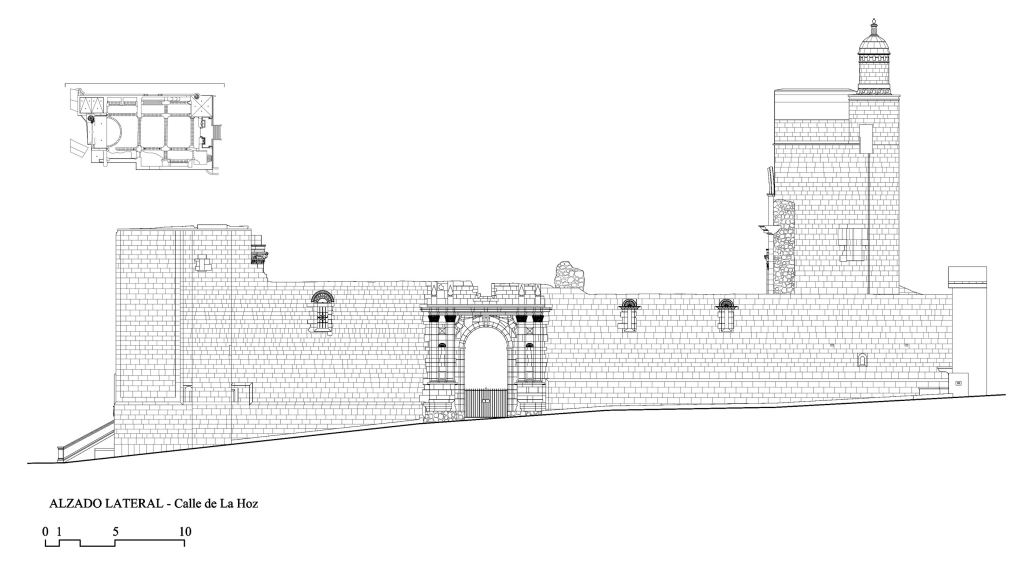

Fig. 14. Alzado de la Iglesia de Santa María de Cazorla bacia calle de La Hoz. (C) Jesús Estepa Rubio sobre el de Pedro Salmerón Escobar

de que si bien es cierto que además de ella existen otras piezas arquitectónicas de relevante valía, son las ruinas de Santa María las que en mayor medida, fruto de su singularidad, categorizan y cualifican un peso importantísimo del valor patrimonial e histórico-artístico comúnmente reconocido por la población.

No es fácil entender la ciudad sin los restos de este edificio, de igual manera que no es fácil entender el edificio sin las singularidades que la ciudad le confiere; y por ello, todo tipo de análisis que profundice en el conocimiento de aspectos ocultos u otros que hayan podido pasarnos desapercibidos, son importantes, no ya sólo para continuar con la puesta en valor de las ruinas a través de su explotación turística y/o cultural, sino que por consiguiente, con ello a la vez se ahonda en el descubrimiento de la propia idiosincrasia ${ }^{26}$ de la ciudad y de sus habitantes.

Con ello, el análisis de la metrología, las proporciones y en general de todos los elementos utilizados para la coordinación y el control de los espacios del hipotético edificio, nos conducen a deducir teorías que sirven para mantener vivos criterios básicos para el adecuado mantenimiento y la correcta conservación de los espacios sacros de la totalidad de la provincia de Jaén, cuanto menos los construidos con similares condiciones que la Iglesia de Santa María de Cazorla.

Además, una vez que se conocen con precisión las medidas y las dimensiones de la totalidad del edificio y de cada una de sus partes, se pueden diseñar con exactitud y sin perder la identidad del bien patrimonial, piezas que puedan sustituir aquellas pocas que por su mal estado o por su situación inestable por deterioro, pudieran poner en entredicho la estabilidad y la seguridad de los restos monumentales y con ello se produjera un pérdida mayor o incluso la imposibilidad de continuar con las visitas públicas turísticas y culturales y por ende, dando difusión al conocimiento de su valor histórico y artístico.

${ }^{26}$ La ciudad de Cazorla ha sido constantemente analizada desde diferentes enfoques y con procedimientos de trabajo y estudio muy variados, pero en todos y en cada uno de ellos la figura de las ruinas de la Iglesia de Santa María de Cazorla siempre acaba adquiriendo un protagonismo inexcusable que de alguna manera termina por condicionar no ya solo decisiones de diseño y organización espacial tomadas para la planificación urbanística de la ciudad, sino también comportamientos cotidianos que se recogen y se concentran en su entorno inmediato, tradición que se ha venido manteniendo en el lugar desde que se comenzaron las obras.

Así pues, documentos como el trabajo del arquitecto cazorleño Luis Cano, en el primer Plan General de Ordenación Urbana redactado para la ciudad en el año 1975, verifican la idea de que las ruinas de la Iglesia de Santa María de Cazorla constituyen para la ciudad un eje motor en torno al cual se deben planificar la mayor parte de los requerimientos arquitectónicos y urbanos de la ciudad antigua de Cazorla.

No en balde, Pablo Carazo Martínez de Anguita y Miguel Ruiz Calvente, casi veinte años más tarde, con la redacción del documento para la categorización y delimitación del conjunto histórico de la ciudad, vienen a validar las mismas conclusiones respecto de la importancia de las ruinas en la configuración formal y en el entendimiento del conjunto histórico de Cazorla, cuya relación biunívoca queda manifiestamente remarcada. 


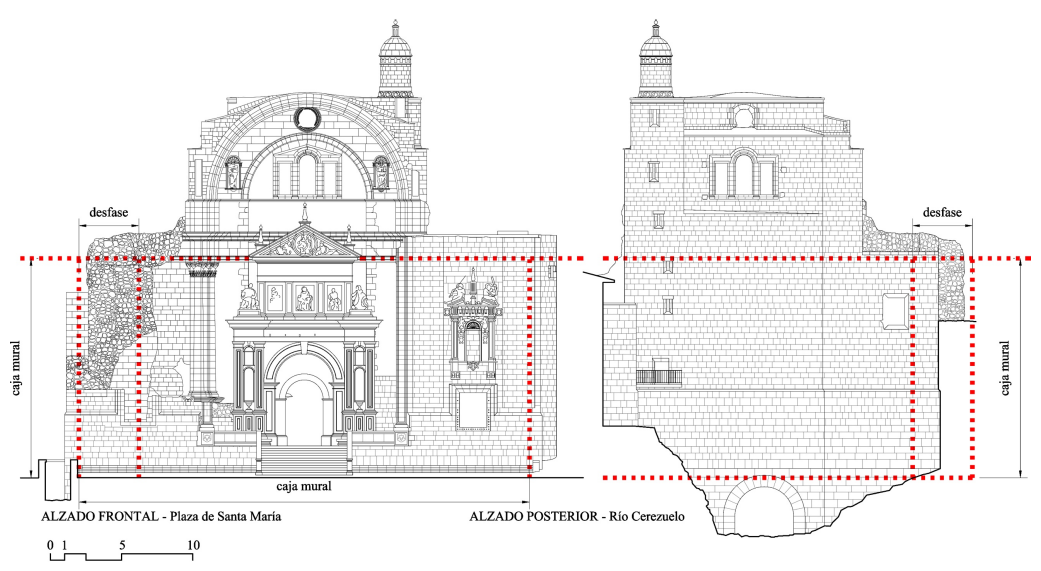

Fig. 15. Análisis de proporciones. Caja mural de las ruinas de la Iglesia de Santa María de Cazorla. C Jesús Estepa Rubio sobre el de Pedro Salmerón Escobar.

Garantizar el futuro de un bien arquitectónico pasa siempre por comprender sus orígenes y sus cuestiones definitorias y diferenciadoras; y en ello, el razonamiento constructivo y proyectual del que surgió tal arquitectura juega un papel fundamental. No cabe duda de que para el proyecto, y más aún para los principios de rigor laboral y la sistematización de procesos característicos de los arquitectos renacentistas, la métrica, las relaciones numéricas y la coordinación modular, siempre fueron determinantes y a la vez condicionantes para el aspecto final, tanto del espacio interior como de la apariencia física en la escena urbana de cada edificio. Es consecuencia de ello que resulta casi obligado pararse a comprender cada medida de cada parte del edificio para garantizar que éste perdure en el tiempo.

Más allá sucede con las ruinas de la Iglesia de Santa María de Cazorla, pues al no haberse concluido la obra, siempre quedaría la tentación de querer finalizarla a posteriori, y aun cuando tales planteamientos pudieron haber tenido sentido en el pasado, hoy día resultan caducos y obsoletos, hasta el punto tal de que llegar a ese escenario sería un gravísimo error, no sólo para la conclusión de la complexión arquitectónica y formal del elemento, sino para el mismo entendimiento histórico y conceptual de lo que tal construcción es. Sin embargo, su valía arquitectónica y patrimonial igualmente tiene que ser salvaguardada, y sin duda alguna, herramientas como el dibujo y la toma de datos a través de la metrología y el análisis de los controles espaciales considerados para la creación del templo, constituyen parte de los trabajos de revisión y de supervisión que de forma paulatina y constante hay que aplicar al monumento.

En raras ocasiones hemos visto analizadas, de forma específica y determinista, cuestiones relacionadas con la métrica y el control numérico del espacio, aplicadas de manera lineal y con un discurso uniforme, sobre la arquitectura de Andrés de Vandelvira ${ }^{27}$. El trabajo sobre la metrología y los mecanismos de coordinación arquitectónica y de control espacial de la obra sacra de Andrés de Vandelvira, podría ayudar a extraer conclusiones que puedan acercar edificaciones, no ya sólo por la soluciones formales empleadas o por la simple visión

27 Ortega Suca traza relaciones métricas y líneas guía de coordinación y proporcionalidad espacial para la Catedral de Jaén, y con ello abunda en numerosísimas relaciones dimensionales que se pueden encontrar en varios elementos del templo, especialmente aquellos relacionales con su perímetro murario y sus fachadas exteriores. Este es uno de los pocos casos de la arquitectura sacra del Renacimiento de la provincia de Jaén que ha sido analizado desde esta óptica; sin embargo, debido a los objetivos particulares del trabajo de Ortega Suca, así como a las especiales condiciones de este edificio, tanto por estilo arquitectónico, como por escala, así como por lo dilatado de su construcción en el tiempo, no podemos considerarlo como un ejemplo de aplicación directa al trabajo que nos ocupa. No obstante es necesario aclarar que su metodología y los planteamientos derivados de su enfoque eminentemente gráfico, son de especial interés y utilidad para la presente investigación, de modo tal que podrían extrapolarse a otras edificaciones más próximas a las ruinas de la Iglesia de Santa María de Cazorla en cuanto a escala, ubicación geográfica y/o categorización constructiva. 


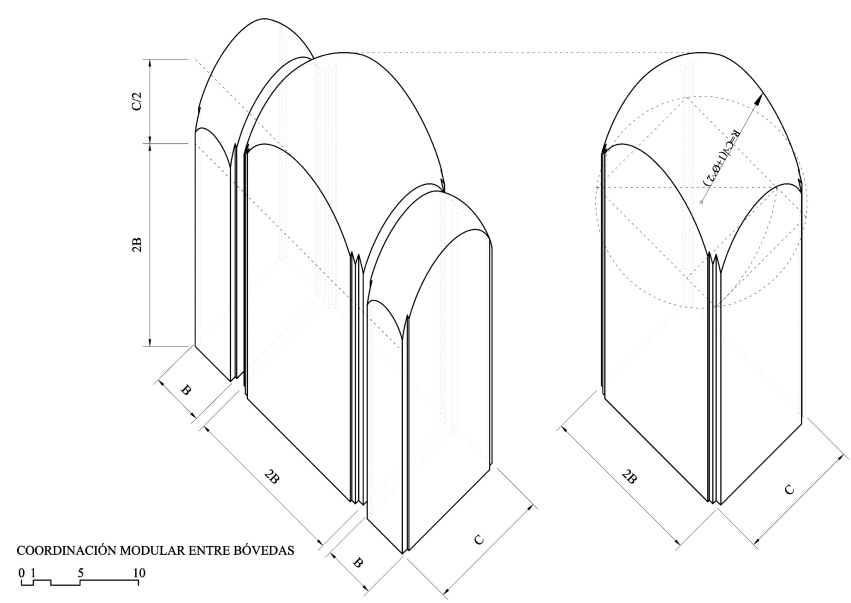

Fig. 16. Esquema de cubrición espacial mediante bóvedas para la Iglesia de Santa María de Cazorla. (C) Jesús Estepa Rubio

historicista de haber tenido fases de construcción coetáneas, sino por otros matices considerados por el arquitecto antes del comienzo de la fase de obra; es decir, podría llevarnos a sacar conclusiones más generalizadas sobre la manera de pensar del maestro alcaraceño, sobre su ratiocinatio.

No obstante, la aplicación directa de esta investigación sin embargo es muchísimo más inmediata e incluso visual. Puesto que se trata de unas ruinas, y por lo tanto los espacios definitorios de las mismas no están concluidos, la determinación de todas las relaciones de proporcionalidad nos han llevado a tener conocimiento sobre cosas que no llegaron a suceder, y aunque pudieron haber sido modificadas a posteriori, aquellas parecen bastante evidentes, no sólo por cumplir los mandatos del proceder proyectual de las reglas de los órdenes clásicos, sino porque además las podemos comprobar en otros muchos edificios concluidos cuya autoría es compartida y cuyas condiciones de partida y de contorno comparten un alto porcentaje de rasgos comunes.

Ello arroja una conclusión de notable importancia, que no es otra que el hecho de que del análisis del control espacial, podemos deducir inexorablemente las condiciones volumétricas de tal espacio, a pesar de que éste no hubiere sido jamás finalizado. Es decir, de la mano de las relaciones de volumen y medida llega a nosotros la definición de la complexión del espacio de la iglesia; de las ruinas se deduce un espacio.

De este modo, al haber estudiado las relaciones establecidas entre las plantas, los alzados y las secciones de la iglesia se pueden reconstruir unidades espaciales mínimas que por adición pueden servir para tener un conocimiento completo de la totalidad del espacio interior de la iglesia.

Visto cuanto antecede, y teniendo en cuenta los criterios que se definían como base deductiva para el método de trabajo, podemos hacer una primera aproximación tridimensional de la geometría del espacio interior de la Iglesia de Santa María de Cazorla.

En la axonometría que se acompaña se ha representado el volumen del vaciado del espacio perceptible de la iglesia desde el interior, es decir, se trata del negativo espacial que resultaría moldeado si consideramos que los elementos arquitectónicos construidos son los moldes que generan tal tallado. En tal representación se han obviado los elementos decorativos, atendiendo exclusivamente a la geometría total del espacio y simplificando detalles completos que sólo podrían comprenderse a pequeña escala.

El volumen total del vaciado del espacio interior de la iglesia se encuentra a su vez circunscrito por otro volumen que representa el volumen máximo capaz que el edificio arroja a la estructura urbana; con ello puede establecerse no ya sólo una relación comparativa ente 


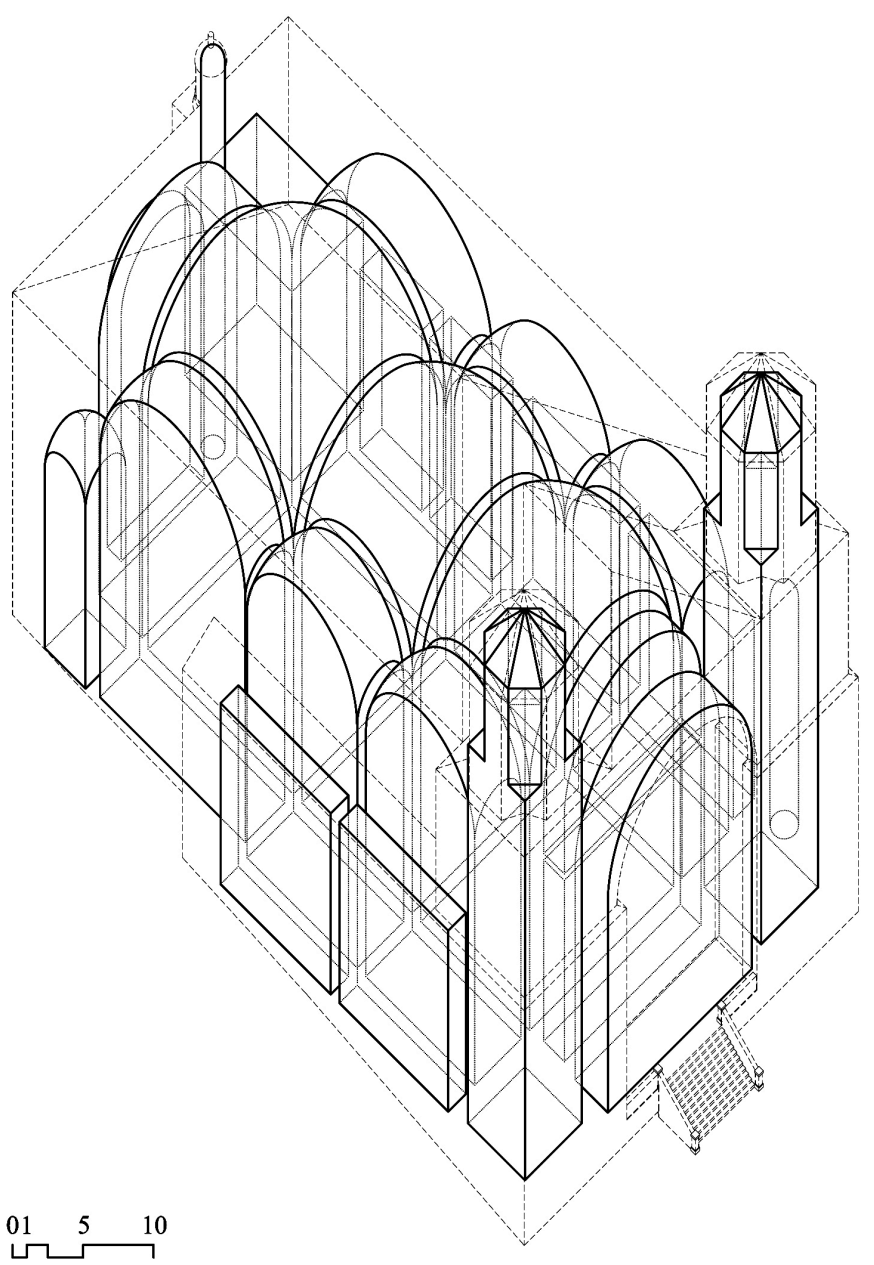

Fig. 17. Relación volumétrica entre las complexiones espaciales del interior y del exterior la Iglesia de Santa María de Cazorla. (C) Jesús Estepa Rubio.

los diferentes espacios con respecto al total del edificio, sino tener criterio de grosores e incluso matices de corporeidad constructiva, ya sea está de carácter tectónico o añadidos suplementarios ligeros que conformen determinados métodos constructivos, la mayoría de ellos de carácter artesanal.

Es una representación abstracta de la tremenda importancia que para entender el edificio tiene la componente espacial que puede leerse del mismo.

Con ello pues se puede concluir el trabajo de análisis dimensional y de las relaciones de proporciones entre ellas con un escenario perfecto y adecuado que permitiría comenzar labores de detalle encaminadas a conseguir una reconstrucción, no ya sólo del espacio de las de la iglesia, sino de la propia iglesia en sí; de manera tal que empleando modernas herramientas informáticas de recreación virtual, se podría tener un conocimiento perfecto y detallado de cómo debería haber sido la iglesia en la hipótesis de que ésta hubiera podido ser acabada. Es decir, el notable interés que podemos deducir de esta labor plantea una prospectiva de futuro que puede ser continuada en el tiempo casi sin límite alguno, hasta llegar a tener una visualización fotorrealista de alta calidad y al máximo detalle al que la técnica permita llegar. 
Referencias bibliográficas

Barbé-Coquelin de Lisle, G.,. El tratado de arquitectura de Alonso de Vandelvira: Edición con introducción, notas, variantes y glosario hsipano-francés de arquitectura. Madrid: Confederación Española de Cajas de Ahorros. (1977)

Baxandal, M.,:Pintura y vida cotidiana en el Renacimiento. Madrid. Ed. Gustavo Gili. ISBN: 84252-0734-7. (1978)

Bonet Correa, A.: Andalucia Monumental: arquitectura y ciudad del Renacimiento y el Barroco. Sevilla: Editoriales Andaluzas Unidas. (1986)

Calvo López, J.: El manuscrito Cerramientos y Trazas de Montea de Ginés Martínez de Aranda. Archivo Español de Arte LXXXII, 325, (2009), pp. 1-18.ISSN: 0004-0428.

Carreras Soto, T.: Trazado de los cinco órdenes de arquitectura. Sevilla. Ed. Casa Carreras. (1952)

Chueca Goitia, F.: Andrés de Vandelvira, Arquitecto. Jaén: Riquelme y Vargas. (1995).

Díaz Moreno, F.: Tratados españoles de arquitectura en la Universidad Complutense. Anales de Historia del Arten ${ }^{\circ}$ 5, (1995), pp. 189-204.

Esteban Lorente, J. F.: La teoría de la proporción arquitectónica en Vitruvio, Revista Artigrama, núm. 16, (2001), p. 229-256, ISSN: 0213-1498.

Esteban Lorente, J. F.: "El control del espacio arquitectónico en las iglesias salón españolas". Arquitectura religiosa del siglo XVI en España y Ultramar, (2004), pp. 85114, ISBN: 84-7820-735-X. Zaragoza. Institución Fernando El Católico. Excma. Diputación de Zaragoza.

Estepa Rubio, A. y Estepa Rubio, J.: “Análisis geométrico y espacial de la ruinas de la Iglesia de Santa María de Cazorla, obra atribuida al arquitecto Andrés de Vandelvira". Arte en las ciudades, las ciudades en el arte. Zaragoza: Universidad San Jorge, (2013), pp. 39-63

Estepa Rubio, A. y Estepa Rubio, J.: Figuración y teatralidad en las estructuras de comunicación vertical propuestas por los Vandelvira. Estudio formal y analítico del caracol de emperadores como caso teórico singular. Revista EGA. ISSN: 1133-6137. Valencia: Departamento de Expresión Gráfica Arquitectónica. Universidad Politécnica de Valencia, ( 2017)

Estepa Rubio, A. y Estepa Rubio, J.: Idealización tipológica y estilística por comparación para el estudio de los soportes en la arquitectura sacra giennense. Propuesta de reconstrucción para el caso de las ruinas de la Iglesia de Santa María de Cazorla. Revista EGA. ISSN: 1133-6137. Valencia: Departamento de Expresión Gráfica Ảrquitectónica. Universidad Politécnica de Valencia. (2017)

Galera Andreu, P. A.: Andrés de Vandelvira. Tres Cantos (Madrid): Akal. (2000)

García, S.: Compendio de arquitectura y simetría de los templos conforme a la medida del cuerpo humano". (1681)

García Morales, M. V.: Arquitecto y arquitectura en los tratados españoles del siglo XVII. Espacio, tiempo y forma, serie VII Historia del Arte, no 2, (1989), pp. 115-132. Madrid. Universidad Nacional de Educación a Distancia UNED.

García Morales, M. V.: La figura del arquitecto en el siglo XVII.[Tesis doctoral]. Madrid. Universidad Nacional de Educación a Distancia UNED. (1989).

García Valldecabres, J.: La Métrica y las trazas en la iglesia de San Juan del Hospital de Valencia. [Tesis doctoral]. Valencia. Universidad Politécnica de Valencia, (2010)

Gentil Baldrich, J.M.,. Perspectiva cónica e ideología en el Arte. A través de la mirada: anatomía, arquitectura y perspectiva en la tradición artística occidental.ISBN: 978-8415289-89-0, (2014), pp. 145-186. Madrid: Ed. Abada.

Hodgson Torres, M. L.: Dibujo y conocimiento. La investigación a través de la forma. Revista ARSDIDAS, número 1, Tenerife. Depósito Legal TF2336/2004, ISSN: 1698-9074. (2004)

Juan García, N.: Los tratados de arquitectura como modelos constructivos. La influencia de la Regola de Vignola y su copia en un libro de trazas aragonés. Actas del VII Congreso 
Nacional de Historia de la Construcción. Santiago de Compostela 26 al 29 de Octubre de 2011. (2011), pp. 687-698.

Kurent, T.: The modular composition of roman water wheels. Revista Archaeometry, $\mathrm{n}^{\circ} 10$, (1967), pp. 24-34. Oxford: Universidad de Oxford.

Kurent, T.: Thevitruvian symmetria mean modular sizes, revista Lingüística ${ }^{\circ}$ 19, (1979), pp. 65-78. Ljubljana: Facultad de Arte. Universidad de Ljubljana. ISSN: 0024-3922

Kurent, T.: La coordinación modular de las dimensiones arquitectónicas. Boletín del Museo Arqueológico Nacional, $\mathrm{n}^{\mathrm{o}}$ 1, tomo III, (1985), pp. 69-65. Madrid: Ministerio de Educación, Cultura y Deporte. Museo Arqueológico Nacional.

Loss, A.: Arquitectura (1910)

Molina Reyes, B.; Salmerón Escobar, P.: Restauración de las Ruinas de Santa María de Cazorla. Granada: Consejería de Cultura. Junta de Andalucía (2010)

Morris, W.: Prospects of Architecture in Civilization (1881)

Paccioli, L.: De divina proportione. (1496)

Palestini, C.: Las investigaciones sobre las proporciones para el control formal de la arquitectura. Actas del Tercer Congreso Nacional de Historia de la Construcción. Sevilla. Universidad de Sevilla. Junta de Andalucía. (2000)

Palacios Gonzalo, J. C:. Trazas y cortes de cantería en el Renacimiento Español. Madrid: Ministerio de Cultura. Dirección General de Bellas Artes y Archivos. Instituto de Conservación y Restauración de Bienes Culturales. (1990)

Raya Moral, B.: La arquitectura vandelviriana en la provincia de Jaén. Aportación a su estudio gráfico.Jaén: Diputación provincial de Jaén. Instituto de Estudios Giennenses. ISBN: 97884-92876-52-5. (2015).

Reyes Iglesias, M. E.: Arte y Naturaleza en clave geométrica. Valladolid: Departamento de Matemática Aplicada. Universidad de Valladolid. (2010)

Ruskin, J.: Las siete lámparas de la arquitectura. (1849)

Sierra Delgado, R.: De Granada a Úbeda pasando por Verona. Un viaje exploratorio por la forma siloesca de capilla rotonda. Valencia: Revista E.G.A. no 14, (2009), pp. 166-175.

Sierra Delgado, R.: Diego de Siloé y la Nueva Fábrica de la Sacristía Mayor de la Catedral de Sevilla. Sevilla: Secretariado de publicaciones de la Universidad de Sevilla. (2013)

Valls Mora, M.: Las traslación de la modulación y las proporciones en Arquitectura. De Vitruvio a Villard de Honnecourt. El caso de Santa Magdalena D’Empúries.Revista Medievalia, no 16, (2013), pp. 171- 186. Barcelona, ISSN: 0211-3473.

Wittkower, R.: Los fundamentos de la arquitectura en la edad del humanismo. Madrid: Ed. Alianza. (1995) 